\title{
A Multi-level Modeling Framework to Study Hepatic Perfusion Characteristics in case of Liver Cirrhosis
}

\section{Geert Peeters $^{1}$, Charlotte Debbaut ${ }^{1}$, Pieter Cornillie ${ }^{2}$, Thomas De Schryver ${ }^{3}$, Diethard}

\section{Monbaliu ${ }^{4}$, Wim Laleman ${ }^{5}$ and Patrick Segers ${ }^{1}$}

${ }^{1}$ IBiTech - bioMMeda, Department of Electronics and Information Systems, iMinds Medical IT

Department, Ghent University. De Pintelaan 185 - Block B, B-9000 Gent, Belgium

Email: geert.peeters@ugent.be; telephone: (0032) 93323137

${ }^{2}$ Department of Morphology, Faculty of Veterinary Medicine, Ghent University. Salisburylaan

133, B-9820 Merelbeke, Belgium

${ }^{3}$ Centre for X-Ray Tomography, Department of Physics and Astronomy, Ghent University.

Proeftuinstraat 86, B-9000 Gent, Belgium

${ }^{4}$ Abdominal Transplant Surgery, University Hospitals Leuven, \& Department of Microbiology and Immunology, KU Leuven. Herestraat 49, B-3000 Leuven, Belgium

${ }^{5}$ Hepatology, University Hospitals Leuven, \& Department of Liver and Biliopancreatic disorders, KU Leuven. Herestraat 49, B-3000 Leuven, Belgium 
A Mluhti-level Modeling Framework to Study Hepatic Perfusion Characteristics in case of Liver Cirrhosis

\section{Abstract}

Liver cirrhosis represents the end-stage of different liver disorders, progressively affecting hepatic architecture, hemodynamics and function. Morphologically, cirrhosis is characterized by diffuse fibrosis, the conversion of normal liver architecture into structurally abnormal regenerative nodules and the formation of an abundant vascular network. To date, the vascular remodeling and altered hemodynamics due to cirrhosis are still poorly understood, even though they seem to play a pivotal role in cirrhogenesis. This study aims to determine the perfusion characteristics of the cirrhotic circulation using a multi-level modeling approach including computational fluid dynamics (CFD) simulations.

Vascular corrosion casting and multi-level micro-CT imaging of a single human cirrhotic liver generated detailed datasets of the hepatic circulation, including typical pathological characteristics of cirrhosis such as shunt vessels and dilated sinusoids. Image processing resulted in anatomically correct 3D reconstructions of the microvasculature up to a diameter of about $500 \mu \mathrm{m}$. Subsequently, two cubic samples $\left(150 \times 150 \times 150 \mu \mathrm{m}^{3}\right)$ were virtually dissected from vascularized zones in between regenerative nodules and applied for CFD simulations to study the altered cirrhotic microperfusion and permeability. Additionally, a conceptual 3D model of the cirrhotic macrocirculation was developed to reveal the hemodynamic impact of regenerative nodules.

Our results illustrate that the cirrhotic microcirculation is characterized by an anisotropic permeability showing the highest value in the direction parallel to the central vein $\left(k_{d, z z}=1.68 \mathrm{x}\right.$ $10^{-13} \mathrm{~m}^{2}$ and $k_{d, z z}=7.79 \times 10^{-13} \mathrm{~m}^{2}$ for sample 1 and 2 , respectively) and lower values in the 
A Multi-level Modeling Framework to Study Hepatic Perfusion Characteristics in case of Liver Cirrhosis

circumferential $\left(k_{d, \vartheta \vartheta}=5.78 \times 10^{-14} \mathrm{~m}^{2}\right.$ and $k_{d, \vartheta \vartheta}=5.65 \times 10^{-13} \mathrm{~m}^{2}$ for sample 1 and 2 , resp.) and radial $\left(k_{d, r r}=9.87 \times 10^{-14} \mathrm{~m}^{2}\right.$ and $k_{d, r r}=5.13 \times 10^{-13} \mathrm{~m}^{2}$ for sample 1 and 2 , respectively) direction. Overall, the observed permeabilities are markedly higher compared to a normal liver, implying a locally decreased intrahepatic vascular resistance (IVR) probably due to local compensation mechanisms (dilated sinusoids and shunt vessels). These counteract the IVR increase caused by the presence of regenerative nodules and dynamic contraction mechanisms (e.g. stellate cells, NO-concentration etc.). Our conceptual 3D model of the cirrhotic macrocirculation indicates that regenerative nodules severely increase the IVR beyond about 65 vol\% of regenerative nodules.

Numerical modeling allows quantifying perfusion characteristics of the cirrhotic macro- and microcirculation, i.e. the effect of regenerative nodules and compensation mechanisms such as dilated sinusoids and shunt vessels. Future research will focus on the development of models to study time-dependent degenerative adaptation of the cirrhotic macro- and microcirculation.

Keywords. human liver cirrhosis, hepatic perfusion, computational fluid dynamics, permeability tensor 
A Multi-level Modeling Framework to Study Hepatic Perfusion Characteristics in case of Liver Cirrhosis

\section{Introduction}

Liver cirrhosis is the end-result of any chronically active liver disease. In this situation, normal liver tissue is gradually replaced by diffuse fibrosis, complete fibrous vascularized septa and regenerative nodules following ongoing parenchymal cell damage, leading to progressively impaired hepatic architecture, perfusion and function [1-4]. Advanced cirrhosis can progress toward end-stage liver failure or hepatocellular carcinoma [5] and accounts annually for an estimated 1.03 million deaths worldwide $[6,7]$. Although several treatments (antiviral therapies, alcohol abstinence etc.) attempt to restrict disease progression and suppress complications, there is no effective treatment for advanced cirrhotic disease and localized hepatocellular carcinoma, except for liver transplantation [8].

The liver has two supplying blood vessels: the hepatic artery (HA) and the portal vein (PV), providing the liver with oxygenated versus nutrient-rich but partially deoxygenated blood, respectively. Both vessels ramify down to the microscale level, consisting of repetitive anatomical units (hexagonal lobules; see Fig. 1 in [9]). Blood is delivered to the lobules via portal tracts (containing terminal HA and PV branches) and flows through the sinusoids, whilst metabolically interacting with the liver cells. Hereafter, blood is collected in the central veins and drained via the hepatic veins (HV) $[10,11]$. Cirrhosis, however, is the progression of fibrosis following the overproduction of extracellular matrix accompanied by changes in angioarchitectural structure with sinusoidal capillarization, (neo-)angiogenesis and shunt formation [12-16]. As these morphological modifications tend to alter the intrahepatic vascular resistance, portal hypertension may arise, which may elicit complications such as ascites, hepatic encephalopathy, varices etc. 
A Multi-level Modeling Framework to Study Hepatic Perfusion Characteristics in case of Liver Cirrhosis

Over the past decades, several experimental studies have focused on cirrhosis-induced angioarchitectural and functional changes. For instance, the multiple-indicator dilution technique demonstrated an impaired exchange between sinusoids and hepatocytes in cirrhotic livers due to sinusoidal collagenization and shunt formation $[14,15,17]$. A variety of imaging techniques (e.g. MRI, CT, ultrasound and microscopy) enabled assessing the microvascular characteristics (a.o. mean transit time, permeability-surface area product) in cirrhotic livers [1823]. Furthermore, Vanheule et al. [16] conducted an intravital fluorescence microscopy study to analyze the interplay between fibrosis and angiogenesis in cirrhotic mice, showing the importance of the vascular endothelial growth factor during cirrhogenesis.

Next to experimental studies, computational models are helpful tools to provide deeper insights in the interaction between the angioarchitecture, perfusion and liver function. To date, numerical research has mainly focused on normal liver perfusion. On the macrocirculatory scale, most existing models examined the hemodynamics in a single vascular tree without considering its interplay with the others (e.g. to study the PV hemodynamics after a right hepatectomy [2426] or the microsphere transport in the HA tree for radioembolization [27]). Additionally, a few studies have simulated the hepatic circulation as a whole based on electrical analog models [2830].

Contrary to the macrolevel, only little research has focused on mathematically modeling the microcirculation, often based on idealized geometries (e.g. mathematical 2D porous medium models of hexagonal lobules [31-33] or a 3D segment of an idealized lobule [34]). Nevertheless, a few studies have investigated the hepatic microcirculation based on anatomically realistic structures using vascular corrosion casts $[9,35]$. Van Steenkiste et al. [35] studied microvascular 
morphological changes and altered macrovascular hemodynamics in portal hypertensive and cirrhotic rodents. Debbaut et al. [9] developed image-based 3D models of a single human hepatic microcirculation to study its perfusion characteristics, enabling the development of a 3D porous medium liver lobule model [36].

As illustrated above, most modeling studies are restricted to normal livers, leaving the questions regarding cirrhotic perfusion unanswered. Since the vascular remodeling and perfusion alterations due to cirrhosis are still poorly understood, an enhanced knowledge of the dysregulated hemodynamics in cirrhotic livers could provide novel insights in cirrhotic liver disease.

The objective of this study is to investigate the perfusion characteristics of the cirrhotic circulation based on a multi-level modeling approach using computational fluid dynamics (CFD) simulations. 


\section{Materials and methods}

\section{A. Microcirculation}

The human liver, examined in this study, was discarded for transplantation due to advanced alcohol-induced cirrhosis (Fig. 1a). The microcirculation of this cirrhotic liver was assessed following a methodology previously applied to a normal liver [9]. As part of research related to machine perfusion preservation of the liver, this study was approved by the Ethical Committee of the University Hospitals Leuven (Belgium) and by the Belgian Liver and Intestine Committee.

\section{Vascular corrosion casting and micro-CT imaging}

A freshly prepared polymer solution was simultaneously injected into the cannulated HA and PV until the polymer resin emerged from the HV. The casting fluid contained Batson's \#17 monomer solution, Batson's catalyst, Batson's promoter (Polysciences, Warrington, USA) and monomeric methyl methacrylate (Merck, Darmstadt, Germany). The polymer solutions were supplemented with coloring dyes to visually distinguish between the HA (red) and PV system (blue). Bismuth oxide nanoparticles were added to the HA injectate to induce a contrast difference between both supplying vessel systems on micro-CT images. After polymerization, the liver was immersed in potassium hydroxide $(25 \% \mathrm{KOH})$ to dissolve the tissue surrounding the vessels. After maceration, only the polymerized resin within the vascular tree lumina remained, representing a replica of the liver's vascular system (Fig. 1b).

Two microvascular samples (with dimension of $\pm 1.5 \mathrm{~mm}$ by $1.4 \mathrm{~mm}$ by $1.6 \mathrm{~mm}$ and $\pm 1.1 \mathrm{~mm}$ by $1.9 \mathrm{~mm}$ by $1.5 \mathrm{~mm}$ for sample 1 and 2, respectively) were dissected from the cast from vascularized zones in between regenerative nodules. Both microscopic (Stereo microscope; 
A Nulti-level Modeling Framework to Study Hepatic Perfusion Characteristics in case of Liver Cirrhosis

Olympus SZ with colorview 1 camera and Cell^D software, Hamburg, Germany) and scanning electron microscopic (SEM; JEOL JSM 5600 LV, Jeol, Zaventem, Belgium) examination displayed a microvascular network without extravascular polymer leaks, with the presence of abnormally shaped, often enlarged blood vessels, compatible with shunt vessels which are typically present in liver cirrhosis (Fig. 2a-b). Lacking the typical sinusoidal network, regenerative nodules were observed as empty ellipsoidal regions in the cast (Fig. 2c).

Subsequently, an in-house developed high-resolution micro-CT scanner (UGCT, Ghent University, Ghent, Belgium) was used to scan the microvascular samples at a resolution of $1.9 \mu \mathrm{m}$ and 1.7 $\mu \mathrm{m}$ for sample 1 and 2, respectively [37]. More elaborate details on the vascular casting and micro-CT procedure can be found in [28].

The micro-CT image datasets were segmented and reconstructed in 3D using the software package Mimics (Materialise, Leuven, Belgium). Sample 1 contained seemingly unaffected sinusoids to study the more subtle sinusoidal changes caused by cirrhosis (Fig. 3a). In contrast, sample 2 displayed multiple abnormal, often enlarged, blood vessels, most likely representing shunt vessels (Fig. 3b).

Due to computational limitations, a cube was virtually dissected from the selected samples for the numerical models using Magics (Materialise, Leuven, Belgium). The orientation of each cube was such that its z-axis was approximately parallel to the longitudinal direction of the lobule (central vein direction). The $r$ and $\vartheta$ direction of the cube were oriented according to the radial and circumferential directions, respectively, of the hexagonal lobule cross-section (see [9] for more information). 
A Multi-level Modeling Framework to Study Hepatic Perfusion Characteristics in case of Liver Cirrhosis

\section{Computational fluid dynamics modeling}

Before modeling blood flow through the cubic samples, guidance boxes were added to facilitate numerical convergence and distribute the blood inflow over the inlet sinusoids (Fig. 4; height was equal to $10 \%$ of the sample height). The surface meshes of the cubes were optimized using 3-matic (Materialise, Leuven, Belgium). After the removal of useless noise shells (e.g. detached sinusoidal remnants), the cubes were auto-remeshed, and overlapping and intersecting triangles were removed. Final surface meshes contained approximately $1.2 \times 10^{6}$ triangular elements with a skewness less than 0.5 (Fig. 4). Thereafter, unstructured tetrahedral volume grids were created in TGrid (Ansys, Canonsburg, PA, USA) with approximately $9.5 \times 10^{6}$ tetrahedral cells, a maximal skewness less than 0.95 and an average skewness of 0.27 . Detailed information about the mesh generation can be found in [9].

To estimate the permeability tensor of the cubes, blood flow was simulated through the sinusoidal structure in three orthogonal directions (radial, circumferential and axial directions of the lobule). The CFD software package Fluent 14.0 (Ansys, Canonsburg, PA, USA) was used to solve the steady and laminar flow field.

A flat velocity profile was imposed at the inlet of the model (Fig. 4; top plane of the inflow guidance). Due to a lack of literature data on microcirculatory flow velocities in three orthogonal directions in a cirrhotic liver, the applied inlet velocity was deduced from scaling down the average total liver blood flow $(1450 \mathrm{ml} / \mathrm{min}$; [10]) to the flow entering the dissected sample as is also done in [9], resulting in an inlet velocity $v$ of $2.59 \times 10^{-6} \mathrm{~m} / \mathrm{s}$. The lateral boundaries, consisting of transected sinusoids, were defined as symmetry planes. A zero static pressure boundary condition ( $0 \mathrm{~Pa}$ ) was applied at the bottom of the outlet guidance box and the 
A Mluhti-level Modeling Framework to Study Hepatic Perfusion Characteristics in case of Liver Cirrhosis

sinusoidal lumina were treated as closed no-slip walls. Blood was modeled as an incompressible and homogeneous Newtonian fluid with a density $\rho$ equal to $1050 \mathrm{~kg} / \mathrm{m}^{3}$ and a dynamic viscosity $\mu$ of $3.5 \cdot 10^{-3} \mathrm{~Pa} \cdot \mathrm{s}[9]$.

\section{Calculation of the Permeability Tensor using Darcy's law}

Darcy's law [Eq. 1] was applied to calculate the permeability tensor $K$ of the cubes.

$$
\nabla P=-\frac{\mu}{k} \vec{v}
$$

When rewriting Darcy's law according to the applied flow directions ( $r, \vartheta$ and $z$ ) (see [9] for detailed information), the reformulated Darcy equation (with $i, j$ representing $r, \vartheta$ or $z$ ) [Eq. 2] allowed calculating the coefficients of the permeability matrix based on the dynamic viscosity $\mu$, the characteristic length $L_{i}(\mathrm{~m})$, the pressure difference $\Delta P_{i}(\mathrm{~Pa})$, the volumetric flow rate $Q_{i}$ $\left(\mathrm{m}^{3} / \mathrm{s}\right)$ and the cross-sectional area $A_{i}\left(\mathrm{~m}^{2}\right)$.

$$
k_{i j}=-\mu \frac{L_{j}}{\Delta P_{j}} \frac{Q_{i}}{A_{i}}
$$

To minimize boundary conditions effects, 15 subsampled cubes (with a characteristic length of $50 \mu \mathrm{m}$ ) were further analyzed to calculate the permeability coefficients. These subcubes (as defined in Table 1 of [9]) were oriented such that their lateral boundaries were located at a distance of at least $25 \mu \mathrm{m}$ from the boundaries of the virtually dissected sample.

For every subcube, the mean, standard deviation and median values of each permeability coefficient as well as the 3D sinusoidal porosity (fraction of the volume occupied by sinusoids in the total volume of the cube) were calculated. A Shapiro-Wilk test (SPSS; IBM, Amonk, New York) was conducted to verify whether the permeability coefficients were normally distributed. The permeability tensor was subsequently factorized into eigenvectors and eigenvalues to acquire 
A Multi-level Modeling Framework to Study Hepatic Perfusion Characteristics in case of Liver Cirrhosis

the permeability coefficients along the principal axes. The eigenvectors also enabled calculating the angles between the principal axes and the predetermined coordinate system $(r, \vartheta$ or $z$ ). Elaborate details about the diagonalization of the permeability tensor can be found in the Appendix of [9].

\section{B. Macrocirculation}

In the previous section, the microcirculation CFD models were based on samples including dilated sinusoids (sample 1) and shunt vessels (sample 2). In contrast, regenerative nodules observed as ellipsoidal avascular holes in the vascular replica - were not incorporated into these models. To quantify the impact of these regenerative nodules on the hepatic hemodynamics, we developed a conceptual 3D CFD model of the liver macrocirculation, allowing modeling normal liver perfusion (no nodules) as well as cirrhotic perfusion when including nodules.

\section{Normal liver}

A simplified 3D liver geometry was constructed in pyFormex (in-house open-source software developed at BioMMeda, Ghent University, Gent, Belgium). All vascular trees (HA, PV and HV) were modeled as single bifurcations with dimensions representative for normal livers (Fig. 5a) [38]. A rectangular cuboid volume was used to symbolize the sinusoids and liver tissue surrounding the vascular trees.

An unstructured tetrahedral volume mesh of the geometry was created with ICEM (Ansys, Canonsburg, PA, USA) based on the Octree method, which was optimized by Delaunay refinement. The HA, PV, HV and liver tissue volume were defined as porous media. The volumetric mesh comprised about $1.6 \times 10^{6}$ tetrahedral elements with a maximal skewness less than 0.65 .

\section{G. Peeters et al.}

BIO-14-1475 
A Multi-level Modeling Framework to Study Hepatic Perfusion Characteristics in case of Liver Cirrhosis

Initially, the CFD model was calibrated to perfusion data of a normal liver, as explained below by using a simplified electrical analog model (Fig. 5b) that is based on liver data from [28]. To this end, pressures of $13.3 \mathrm{kPa}(100 \mathrm{mmHg}), 1.33 \mathrm{kPa}(10 \mathrm{mmHg})$ and $0 \mathrm{~Pa}$ were applied at the $\mathrm{HA}$ inlet, PV inlet and HV outlet, respectively. The boundaries of the liver tissue and sinusoids were treated as closed walls (no slip) and blood was modeled as an incompressible and homogeneous Newtonian fluid with a density $\rho$ equal to $1050 \mathrm{~kg} / \mathrm{m}^{3}$ and a dynamic viscosity $\mu$ of $3.5 \times 10^{-3} \mathrm{~Pa} \cdot \mathrm{s}$ [39]. Darcy's law [Eq. 4] was applied to estimate zone-specific isotropic permeability values (k) in order to match the zone-specific vascular resistances to those obtained with the electrical model in [28] for a healthy human liver. This is illustrated for the PV system by Eq. $4-6$, in which the vascular resistance $\left(R_{P V}\right)$ was calculated as the pressure difference over the PV vascular tree $\left(\Delta P_{P V}\right)$ divided by the flow $\left(Q_{P V}\right)$. Darcy's law (Eq. 4) was subsequently subdivided into two parts according to the first (mother vessel) and second (daughter vessels) generation of the PV system (Eq. 5) and rearranged to calculate the corresponding permeability value (Eq. 6). $A_{1 / 2}$ and $I_{1 / 2}$ represent the branch's cross-sectional area and centerline length of the first/second vessel generation, respectively (Fig. 5). Finally, the permeability values were slightly adjusted to correspond to the electrical model, resulting in $2.70 \times 10^{-9} \mathrm{~m}^{2}, 2.22 \times 10^{-8} \mathrm{~m}^{2}, 7.87 \times 10^{-8} \mathrm{~m}^{2}$ and $1.83 \times 10^{-8} \mathrm{~m}^{2}$ for the HA, PV, HV and sinusoidal region, respectively.

$$
\begin{aligned}
& \Delta P_{P V}=\frac{\mu \cdot l}{k \cdot A} Q_{P V} \\
& R_{P V}=\frac{\mu \cdot l_{1}}{k_{P V} \cdot A_{1}}+\frac{\mu \cdot l_{2}}{2 \cdot k_{P V} \cdot A_{2}}
\end{aligned}
$$


A Multi-level Modeling Framework to Study Hepatic Perfusion Characteristics in case of Liver Cirrhosis

$$
k_{P V}=\frac{1}{R_{P V}}\left(\frac{\mu \cdot l_{1}}{A_{1}}+\frac{\mu \cdot l_{2}}{2 \cdot A_{2}}\right)
$$

\section{Cirrhotic liver}

Regenerative nodules were homogenously introduced into the CFD model of the simplified normal liver to study their impact on the vascular resistance (nodular region in Fig. 5a). These nodules (diameters ranging from $6 \mathrm{~mm}$ to $11 \mathrm{~mm}$ ) were created in pyFormex and modeled as impermeable spheres, located inside the liver tissue between the inlets and outlet. The volume percentage of regenerative nodules was gradually increased to estimate the isolated effect of the presence of nodules during the evolution of cirrhosis from a nodular volume percentage (vol\%) of $0 \%$ (healthy liver) up to $82.5 \%$ (severe cirrhosis). The geometry was remeshed for each stage of cirrhosis.

The resulting volumetric meshes ranged from $2 \times 10^{6}$ to $10 \times 10^{6}$ tetrahedral elements and were imported in Fluent. Boundary conditions and permeability values were set equal to those of the normal liver (as described in the previous section).

The pressure drop over the nodular region $(\Delta P)$ was measured by subtracting the average pressure of two predefined planes (Fig. 5a), located proximal (plane 1) and immediately distal (plane 2) to the nodular region. Both planes were created such that they did not intersect with the vascular systems. The blood flow $(Q)$ across the nodular region was determined by measuring the volumetric flow rate through the inflow plane. The vascular resistance over the nodular region could then easily be assessed by Eq. 7.

$$
R=\frac{\Delta P}{Q}
$$




\section{Results}

\section{A. Microcirculation}

The static pressure distributions of both samples (Figs. 6a and 7a for the $r$ direction, Figs. S1 and S4 in the supplemental material for the $\vartheta$ and $z$ direction) indicate that pressures along the $r, \vartheta$ or $z$ flow direction range from 0 to $33 \mathrm{~Pa}, 16 \mathrm{~Pa}$ and $11 \mathrm{~Pa}$ for sample 1 and from 0 to $6 \mathrm{~Pa}, 3 \mathrm{~Pa}$ and 2.6 Pa for sample 2, respectively. Overall, the pressure drop over the cube is markedly lower for sample 2. Additionally, the results illustrate that the pressure drop over the cubes depends on the applied blood flow direction with the highest value in the $r$ direction and the lowest in the $z$ direction. Several sinusoids display an approximately uniform pressure, while others show larger pressure gradients (Figs. 6, 7, S1, S4). This leads to preferential pathways in the geometry along which the vast majority of blood flow is transported (Figs. 6b, 7b, S2 and S5). Due to the imposed symmetry conditions, the preferential paths are mainly located within the central region of the geometry. To reduce the influence of the applied boundary conditions, the hemodynamics of a smaller central cube (characteristic length of $50 \mu \mathrm{m}$; similar to [9]) are further analyzed. Table 1 lists the maximum and mean velocity ( $v$ ) and wall shear stress (WSS) of the central cubes of both samples, indicating that the highest $v_{\max }$ and WSS $_{\max }$ values are found for the $r$ direction and the lowest for the $z$ direction.

The wall shear stress covering the sinusoidal surfaces remained mostly under $1 \mathrm{~Pa}$ (Figs. 6c, 7c, S3 and S6) for every flow direction. Some (small) regions yielded higher wall shear stresses due to narrow channels or preferential pathways. 
A Multi-level Modeling Framework to Study Hepatic Perfusion Characteristics in case of Liver Cirrhosis

The permeability coefficients and porosity of every subsampled cube of sample 1 and sample 2 are listed in supplemental Tables S1 and S2, respectively. The mean sinusoidal porosity of the subcubes was found to be $14.3 \% \pm 3.2 \%$ for sample 1 and $24.6 \% \pm 7.3 \%$ for sample 2 . The Shapiro-Wilk test (significance level of 0.05 ) indicated that for sample 1 two out of nine $\left(k_{\vartheta \vartheta}, k_{z \vartheta}\right)$ and for sample 2 three out of nine $\left(k_{r r}, k_{\vartheta z}, k_{z z}\right)$ permeability coefficients were not normally distributed. Therefore, the permeability tensors of both samples ( $K_{1}$ and $K_{2}$ as depicted in Eqs. (8) and (9) for sample 1 and 2, respectively) were estimated based on the median values to limit the influence of skewed distributions (see also [9]). Additionally, Mann-Whitney U tests were conducted to determine whether $\mathrm{k}_{\mathrm{rr}}, \mathrm{k}_{\theta \mathrm{r}}, . ., \mathrm{k}_{\mathrm{zz}}$ of both samples (i.e. of their 15 subsamples) were different (significance level of 0.05 ), which was the case for the main permeability coefficients $\left(\mathrm{k}_{\mathrm{rr}}, \mathrm{k}_{\theta \theta}, \mathrm{k}_{\mathrm{zz}}\right)$ and $\mathrm{k}_{\theta \mathrm{z}}$.

$$
\begin{aligned}
& K_{1}=\left[\begin{array}{ccc}
9.73 \cdot 10^{-14} & 3.09 \cdot 10^{-15} & 3.71 \cdot 10^{-15} \\
1.59 \cdot 10^{-14} & 7.35 \cdot 10^{-14} & -3.85 \cdot 10^{-14} \\
-6.93 \cdot 10^{-15} & -3.40 \cdot 10^{-14} & 1.53 \cdot 10^{-13}
\end{array}\right] \\
& K_{2}=\left[\begin{array}{lll}
5.36 \cdot 10^{-13} & 1.14 \cdot 10^{-14} & -9.12 \cdot 10^{-14} \\
4.56 \cdot 10^{-14} & 5.50 \cdot 10^{-13} & -1.73 \cdot 10^{-13} \\
4.27 \cdot 10^{-14} & 1.14 \cdot 10^{-13} & 7.72 \cdot 10^{-13}
\end{array}\right]
\end{aligned}
$$

The diagonalized tensors (Eqs. (10) and (11) for sample 1 and 2, respectively) demonstrate that the highest permeability is oriented in the axial direction $\left(k_{z z}\right)$, which is almost parallel to the central vein direction, for both samples. For sample 1, the permeability in the circumferential direction $\left(k_{\vartheta \vartheta}\right)$ is about two times lower compared to the radial direction $\left(k_{r r}\right)$. In contrast, $k_{r r}$ and $k_{\vartheta \vartheta}$ are practically the same for sample 2. 
A Multi-level Modeling Framework to Study Hepatic Perfusion Characteristics in case of Liver Cirrhosis

$$
\begin{aligned}
& K_{1, \text { diag }}=\left[\begin{array}{ccc}
9.87 \cdot 10^{-14} & 0 & 0 \\
0 & 5.78 \cdot 10^{-14} & 0 \\
0 & 0 & 1.68 \cdot 10^{-13}
\end{array}\right] \\
& K_{2, \text { diag }}=\left[\begin{array}{ccc}
5.13 \cdot 10^{-13} & 0 & 0 \\
0 & 5.65 \cdot 10^{-13} & 0 \\
0 & 0 & 7.79 \cdot 10^{-13}
\end{array}\right]
\end{aligned}
$$

The angles between the original coordinate system $(r, \vartheta$ and $z)$ and the principal axes were $12.5^{\circ}, 23.6^{\circ}$ and $21.8^{\circ}$ and $38^{\circ}, 39.1^{\circ}$ and $10.4^{\circ}$ for sample 1 and 2 , respectively. In order to align the original coordinate system with the principal axes, the original coordinate system had to be rotated (counter-clockwise) over $20^{\circ},-8^{\circ}$ and $9.6^{\circ}$ and $10.4^{\circ},-0.2^{\circ}$ and $-38^{\circ}$ around the $r$, $\vartheta$ and $z$ axes for sample 1 and 2 , respectively.

\section{B. Macrocirculation}

The pressure distribution and velocity streamlines of a section through a healthy liver and a liver with severe cirrhosis (nodular vol\% of $81.2 \%$ ) are visualized in Fig. 8 . The results of the CFD models (Fig. 9) indicate that increasing vol\% of regenerative nodules corresponds to higher pressure drops over the nodular region, which is located between the PV/HA and HV, (Fig. 9a) and significantly lower HV outflows (Fig. 9b).

For the simplified normal liver model, the pressure difference over the sinusoidal region is 66.7 $\mathrm{Pa}$ and the hepatic venous outflow amounts $1468 \mathrm{ml} / \mathrm{min}$. In the case of cirrhosis, the pressure over the nodular region increases up to $80.1 \mathrm{~Pa}, 169.5 \mathrm{~Pa}$ and $675.8 \mathrm{~Pa}$, while the HV outflow decreases to $1445.5 \mathrm{ml} / \mathrm{min}, 1353.2 \mathrm{ml} / \mathrm{min}$ and $904.3 \mathrm{ml} / \mathrm{min}$ for a nodular vol\% of $22.7 \%, 60.2 \%$ and $82.5 \%$, hereafter called mild, moderate and severe cirrhosis, respectively. The resulting vascular resistances are 1.27, 2.87 and 17.14 times higher compared to the normal hepatic 
Copyright (c) 20 A Multi-level Modeling Framework to Study Hepatic Perfusion Characteristics in case of Liver Cirrhosis

resistance $\left(2.6 \times 10^{3} \mathrm{~Pa} \cdot \mathrm{s} / \mathrm{m}^{3}\right)$ for mild, moderate and severe cirrhosis, respectively. Hence, regenerative nodules severely increase the intrahepatic vascular resistance (Fig. 9c), especially beyond about 65 vol\%. The exponentially-fitted curves of the pressure difference over the sinusoidal region, the HV outflow and the vascular resistance are indicated in Fig. 9. 
A Multi-level Modeling Framework to Study Hepatic Perfusion Characteristics in case of Liver Cirrhosis

\section{Discussion}

Liver cirrhosis comprises a wide spectrum of pathological characteristics, deteriorating the hepatic perfusion and function. In this study, the impact of a number of typical characteristics for cirrhosis on the hepatic hemodynamics was numerically modeled at different length scales. While numerical microcirculation models - based on vascular corrosion casting - revealed the disturbed microflow patterns due to subtle sinusoidal changes and shunt vessels, the impact of regenerative nodules was not included. Therefore, a novel conceptual macrocirculation model was developed to illustrate the overall hemodynamic changes due to regenerative nodules.

Our microcirculation data suggest that the cirrhotic microcirculation perfusion is nonhomogeneous and anisotropic. Sample 1 was completely anisotropic in terms of permeability showing the highest permeability in the direction parallel to the central vein $\left(k_{z z}\right)$ and lower, but mutually different permeabilities in the radial $\left(k_{r r}\right)$ and circumferential $\left(k_{\vartheta \vartheta}\right)$ direction. Contrary, sample 2 exhibited a more or less isotropic permeability in hexagonal cross-sections of a lobule $\left(k_{r r}\right.$ and $\left.k_{\vartheta \vartheta}\right)$ and a slightly higher permeability along the longitudinal direction $\left(k_{z z}\right)$. Hence, sample 2 shows a lower anisotropic behavior in terms of permeability compared to sample 1 .

Debbaut et al. [9] applied the same methodology to assess the perfusion characteristics of the microcirculation in a healthy liver. The pressure ranges obtained in the $r, \vartheta$ and $z$ flow directions were 0-180 $\mathrm{Pa}, 0-170 \mathrm{~Pa}$ and 0-100 $\mathrm{Pa}$, respectively. Since these pressure ranges clearly exceed those of the cirrhotic samples, it appears that the sinusoidal resistance to blood flow is markedly decreased in the dissected samples of this cirrhotic liver. These observations on the microlevel contradict the pressure and flow measurements of perfusion experiments on the whole organ level [40], indicating that the overall intrahepatic vascular resistance increases due 
A Multi-level Modeling Framework to Study Hepatic Perfusion Characteristics in case of Liver Cirrhosis

to cirrhosis. This discrepancy is most likely a consequence of the presence of regenerative nodules and fibrotic septa, which are not included in the micromodels. The conceptual model of the cirrhotic macrocirculation, on the other hand, demonstrates that inclusion of regenerative nodules significantly increases the intrahepatic vascular resistance, impeding the perfusion of liver tissue with a steep increase beyond 65 vol\%. Hence, we hypothesize that the lower pressure gradients - observed in two cirrhotic microvascular samples - imply a locally decreased resistance due to the presence of compensation mechanisms (dilated sinusoids and shunt vessels in cirrhotic sample 1 and 2, respectively). These compensations most likely counteract the increased IVR of the liver as a whole caused by the regenerative nodules, fibrotic septa and dynamic contraction mechanisms (regulated by stellate cells, NO-concentration levels etc.).

Since the here reported data merely reflect the hemodynamics of only two relatively small dissected samples from one cirrhotic liver, we acknowledge that the aforementioned observations may not be simply generalizable to a complete cirrhotic liver. Though MannWhitney $U$ tests were performed to determine whether both samples were different in terms of permeability characteristics, these tests could not provide conclusive information, as both samples were not oriented in exactly the same direction. Additionally, the cirrhotic liver tissue might be heterogeneous (e.g. potential architectural differences near the liver core versus the liver capsule). Analyzing more samples at dispersed locations from the same as well as different livers might yield a better estimation of the perfusion characteristics, but implies a timeconsuming and labor-intensive process.

The vascular corrosion casting procedure was found to be a suitable method to generate a replica of the cirrhotic vasculature, as the microcirculation was adequately filled with polymer 
A Multi-level Modeling Framework to Study Hepatic Perfusion Characteristics in case of Liver Cirrhosis

solution (Fig. 2). We hypothesize that the known shrinkage of the cast resin was compensated for by machine perfusion prior to casting and the pressure exerted during the injection of the polymer. Indeed, the dimensions (radius, length, etc.) of the sinusoidal network - previously measured using a normal liver cast [38] - were consistent with literature values. Unfortunately, the low-vascularized nodular structures were not included in the cast, raising the need for the cirrhotic macrocirculation model to study the impact of nodules.

A number of assumptions were made when developing the numerical models. Due to computer performance restrictions, relatively small-sized cubic samples were virtually dissected to derive the simulation geometry. The positioning of the cube within the samples was not straightforward, as the cirrhotic angioarchitecture was highly distorted, particularly for sample 2. However, the addition of contrast agent bismuth oxide nanoparticles to the HA injectate allowed identifying portal tracts, as the particles were sieved before entering the sinusoids, which proved useful for sample 2. Considering the difficulties to orient the cube, the original coordinate system was relatively well-aligned to the principal axes, as relatively small rotation angles were required to align both coordinate systems.

Blood was modeled as a Newtonian fluid, even though - at the sinusoidal microlevel - blood behaves like a non-Newtonian fluid with a varying viscosity depending on the diameter of the lumen (Fahraeus-Lindqvist effect) [41]. However, at the sinusoidal level (diameters of $\pm 10 \mu \mathrm{m}$ ), blood approximates the viscosity of blood plasma, being a Newtonian fluid. Hence, inclusion of the viscosity effect would only be of importance to the shear stress levels, while the permeability tensor - which was our main interest - solely depends on geometrically-defined parameters when assuming a Newtonian fluid and geometrically comparable structures [42]. 
A Multi-level Modeling Framework to Study Hepatic Perfusion Characteristics in case of Liver Cirrhosis

The velocity imposed at the inlet of the model was deduced from scaling down the total liver blood flow to the flow entering the dissected sample. However, knowing that calculating the permeability tensor is independent of the applied inflow velocity, we opted to work with the blood flow of normal human livers (1450 $\mathrm{ml} / \mathrm{min})$.

An isotropic permeability was implemented in the conceptual macromodel, even though it was shown that the microcirculation may exhibit an anisotropic permeability. We assumed, however, that the orientation of the remaining lobular structures is location-dependent such that, at the macroscopic level, this anisotropic effect cancelled out and the cirrhotic circulation behaved isotropic in terms of permeability. In addition, the permeability coefficients obtained with the micromodels were not implemented in the macromodels due to dimensional incompatibilities. Coupling of the macro- and microcirculation will be a future challenge. However, bearing in mind that the macromodel was a significantly simplified representation of the actual liver vascular architecture, it was still able to simulate and predict the impact of regenerative nodules, corroborating our hypothesis about compensation mechanisms at the microlevel.

Finally, other aspects such as molecular and dynamic processes (stellate cells, NO-concentration etc.) were not included in our model, but could be the topic of future research. At this moment, we only considered the static vascular structure, as our analysis of cirrhotic liver disease focuses on the biomechanical aspects.

Given the fact that the studied liver represents only a single patient-specific snapshot along the pathological pathway of cirrhosis, information on the interplay between the progression of cirrhosis and the architectural disarrangement could not be deduced. Our future research will entail studying the whole disease spectrum going from a normal liver to a full-blown cirrhotic 
A Multi-level Modeling Framework to Study Hepatic Perfusion Characteristics in case of Liver Cirrhosis

liver, using an established rat model to investigate the angioarchitecture and fluid dynamics over the course of events leading to cirrhotic liver disease [43]. At controlled time points, liver casts will be made and multiple samples will be studied using the casting and micro-CT methodology. This experimental setup will enable studying the spatial heterogeneity of the microperfusion in a controlled way and using higher number of samples. Furthermore, it will allow finding the link between disease progression and microstructural disturbances. A better insight in the liver perfusion and hemodynamics might help to define the "point-of-no-return" in cirrhotic patients, beyond which the disease is assumed to be irreversible. Moreover, this may enable the development of patient-specific macromodels. Such a chronological multi-level framework may also be extended to other hepatic diseases (e.g. hepatocellular carcinoma).

\section{Conclusions}

Multi-level numerical modeling allows quantifying the perfusion characteristics of the cirrhotic macro- and microcirculation. Our morphological and numerical results suggest the presence of local compensation mechanisms (i.e. shunt vessels and dilated sinusoids) to counteract the increased vascular resistance (mainly due to the presence of regenerative nodules) of the liver as a whole. Moreover, these local compensation mechanisms seem to be characterized by anisotropic permeability properties, showing the highest value in the direction parallel to the central vein. Generally, the observed permeability values are notably higher compared to a normal liver. 


\section{Tables}

Table 1: The maximum and mean values of the velocity magnitude and wall shear stress for the smaller central cubes.

\begin{tabular}{|c|c|c|c|c|}
\hline Flow direction & $v_{\max }(\mathrm{m} / \mathrm{s})$ & $v_{\text {mean }}(\mathrm{m} / \mathrm{s})$ & $W S S_{\max }(\mathrm{Pa})$ & $W S S_{\text {mean }}(\mathrm{Pa})$ \\
\hline \multicolumn{5}{|c|}{ Smaller central cube 1} \\
\hline$r$ & $5.0 \times 10^{-4}$ & $9.4 \times 10^{-5}$ & 1.7 & $2.2 \times 10^{-1}$ \\
\hline$\vartheta$ & $3.3 \times 10^{-4}$ & $4.3 \times 10^{-5}$ & 1.5 & $1.2 \times 10^{-1}$ \\
\hline$z$ & $1.7 \times 10^{-4}$ & $3.6 \times 10^{-5}$ & $4.8 \times 10^{-1}$ & $9.5 \times 10^{-2}$ \\
\hline \multicolumn{5}{|c|}{ Smaller central cube 2} \\
\hline$r$ & $1.9 \times 10^{-4}$ & $2.0 \times 10^{-5}$ & $3.3 \times 10^{-1}$ & $3.7 \times 10^{-2}$ \\
\hline$\vartheta$ & $1.3 \times 10^{-4}$ & $1.3 \times 10^{-5}$ & $3.7 \times 10^{-1}$ & $2.1 \times 10^{-2}$ \\
\hline$z$ & $0.9 \times 10^{-4}$ & $2.3 \times 10^{-5}$ & $3.2 \times 10^{-1}$ & $4.5 \times 10^{-2}$ \\
\hline
\end{tabular}




\section{Figures}
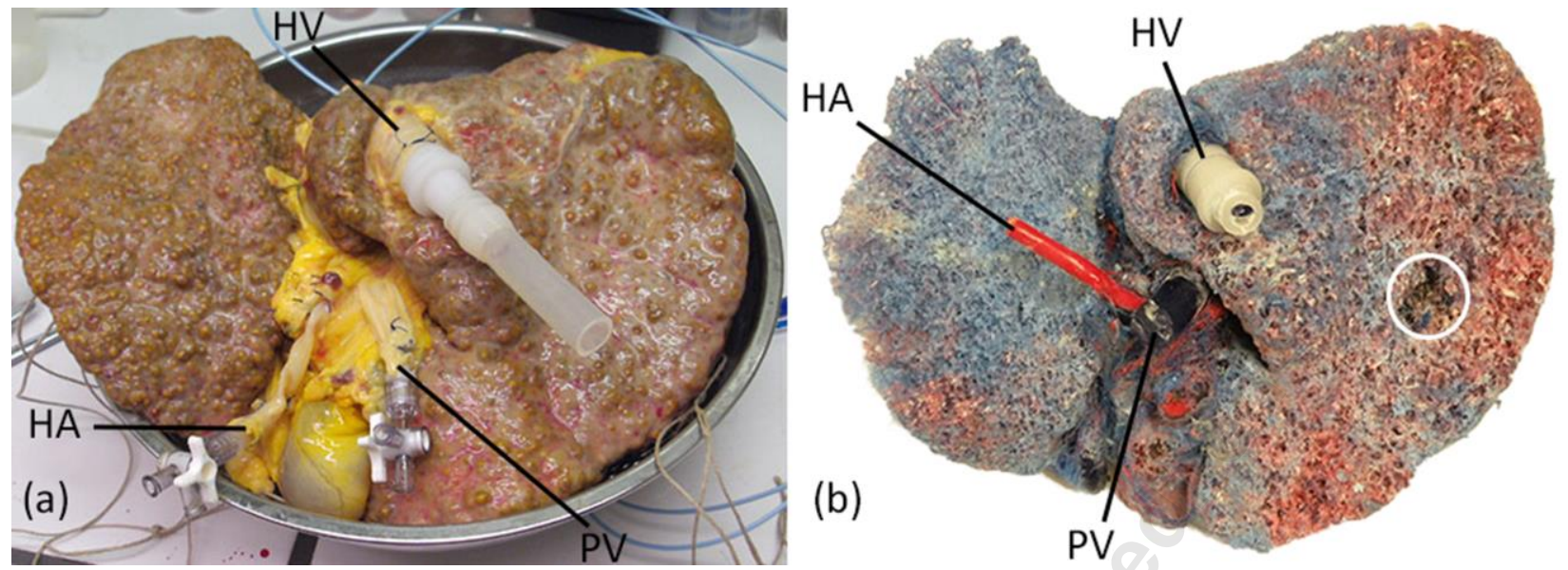

Figure 1: Cirrhotic liver (a) and the corresponding vascular corrosion cast (b). Smaller samples were dissected from the cast (white ellipse) to analyze the microcirculation.
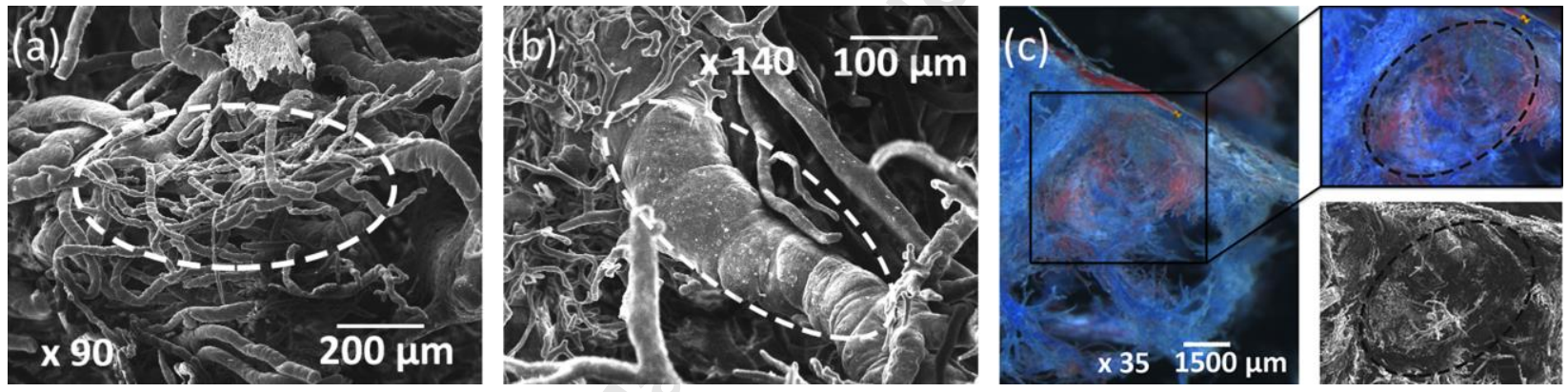

Figure 2. Microscopic analysis of the cirrhotic angioarchitecture: scanning electron microscopic

(SEM) image of enlarged, irregularly shaped intrahepatic vessels, most likely representing shunt vessels (a; dashed circle) causing blood flow to bypass hepatocytes, and an abnormal and bumpy blood vessel lumen (b; dashed circle). Microscopic images (c; left and top right) and a SEM image (c; bottom right) show ellipsoidal holes which become visible after the maceration of the tissue in regenerative nodules, illustrating the compressed walls. 

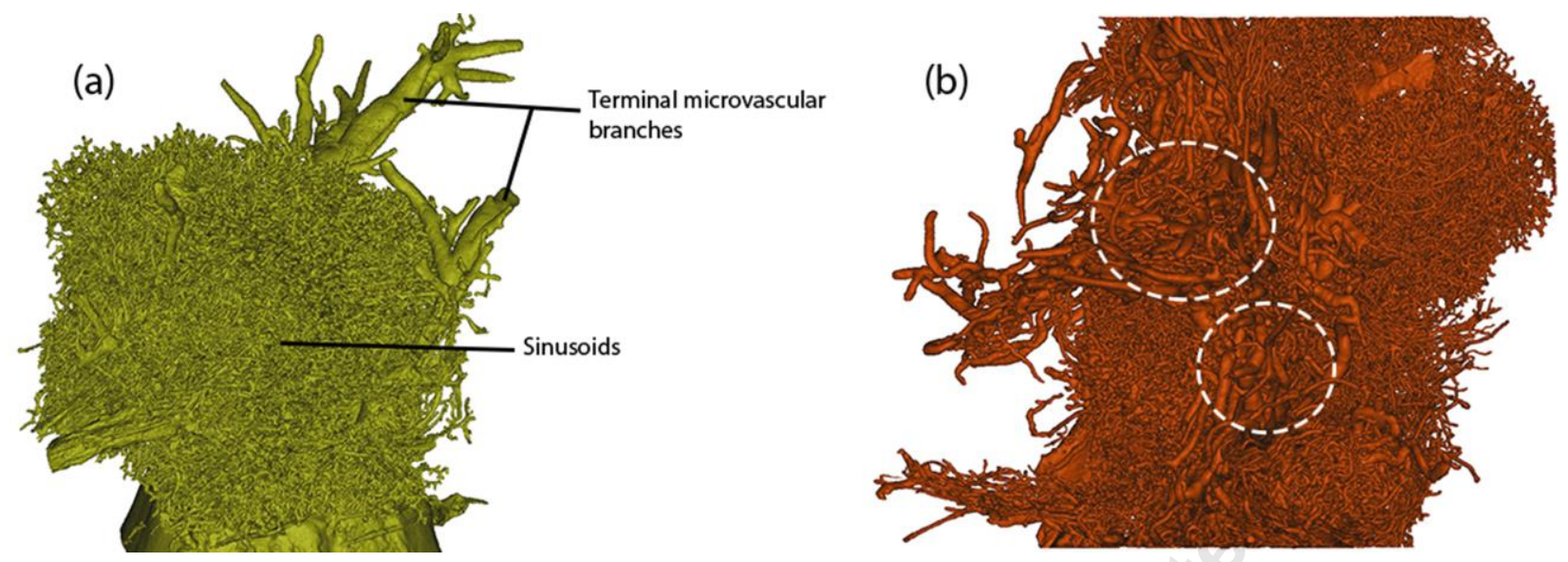

Figure 3. 3D reconstructions of dissected samples of the cirrhotic microvasculature based on micro-CT images: (a) sample 1 [resolution of $1.9 \mu \mathrm{m}$ ] containing seemingly unaffected sinusoids and (b) sample 2 [resolution of $1.7 \mu \mathrm{m}$ ] displaying abnormal shunt vessels (dashed circles).
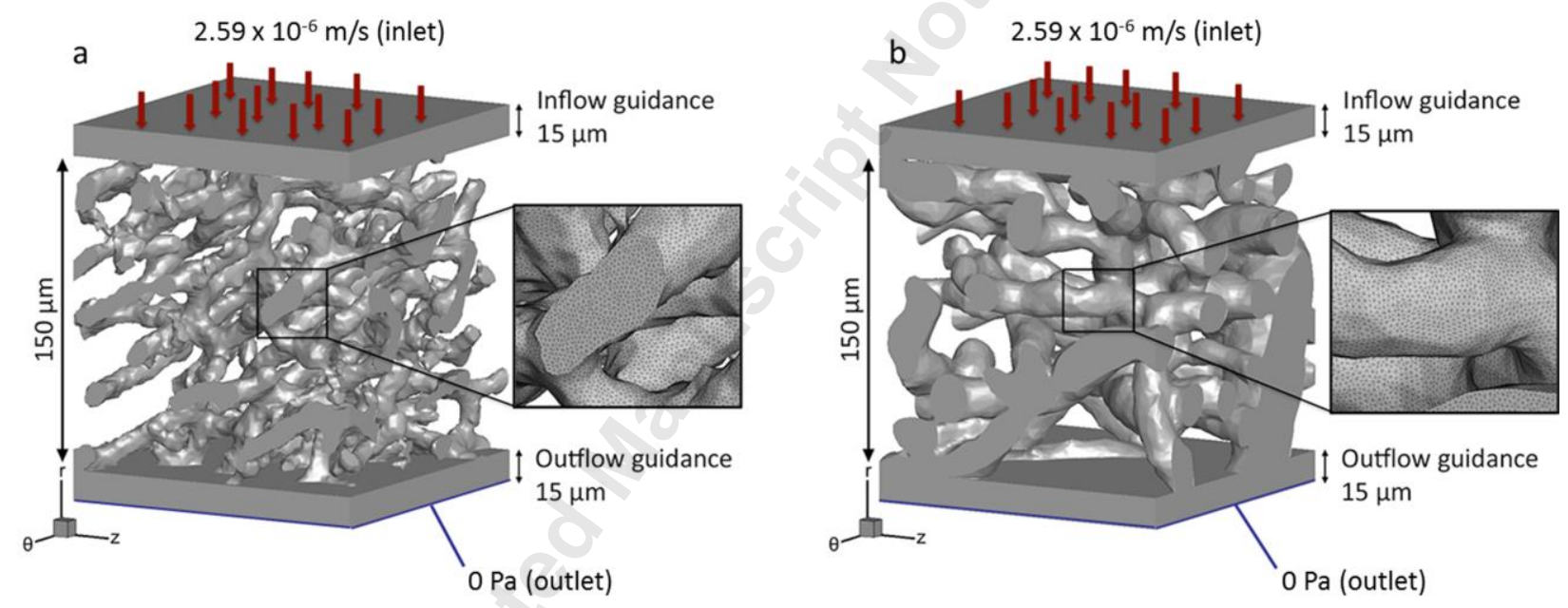

Figure 4. Fluid domain in $r$-direction for sample 1 (a) and sample 2 (b). Inflow and outflow guidance boxes were added to facilitate solution convergence. The surface mesh density of both samples is displayed in the smaller frames. The red arrows indicate the flow direction (from top to bottom). The lateral boundaries were defined as symmetry planes. 


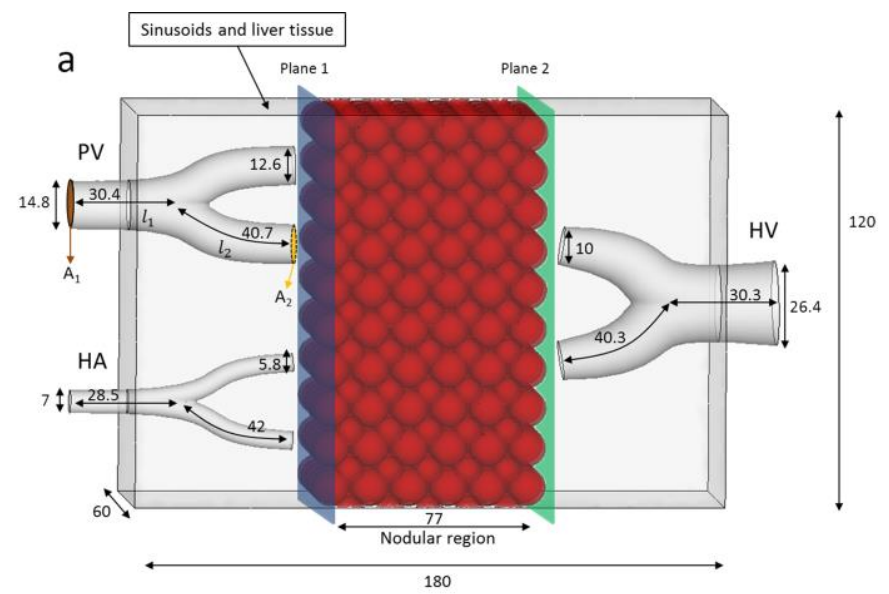

b

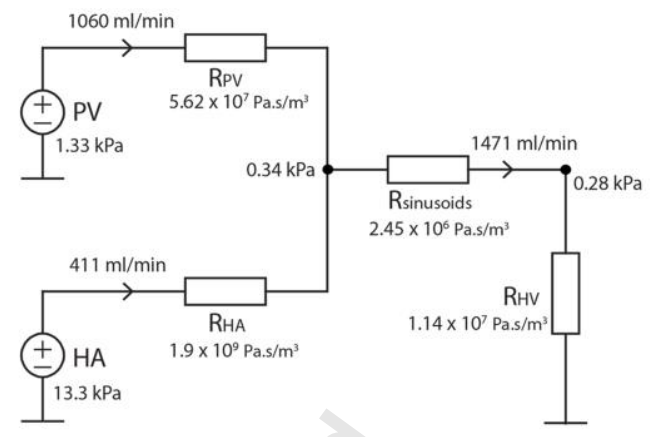

Figure 5. Macrocirculation model of liver cirrhosis: (a) conceptual 3D model of the cirrhotic macrocirculation; $A_{1 / 2}$ and $I_{1 / 2}$ represent the branch's area and length for the first and second vessel generation, respectively. The indicated dimensions are shown in millimeter (mm). (b) Simplified electrical analog model of a healthy liver [28].
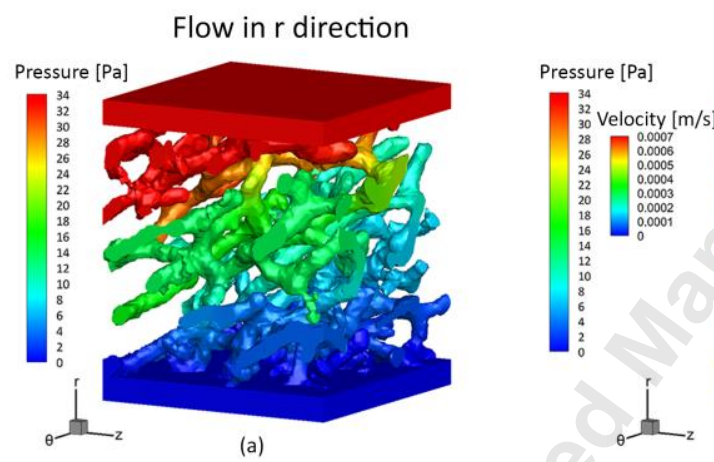

Flow in r direction

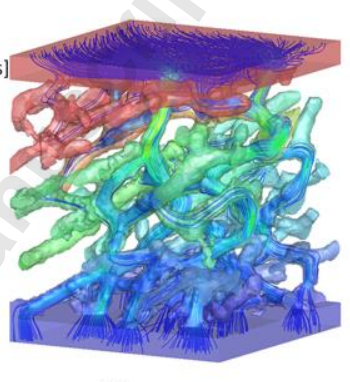

(b)
Flow in r direction

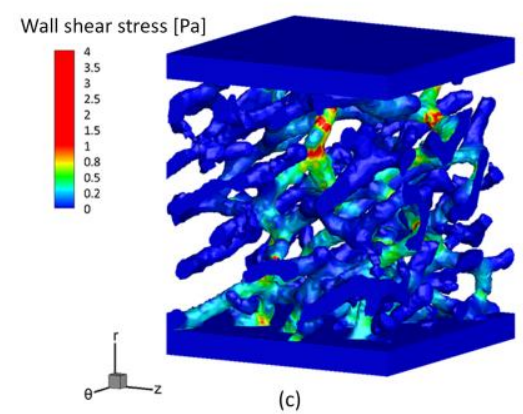

Figure 6. CFD models of cirrhotic sample 1 in the $r$ direction: (a) Static pressure distribution on the sinusoidal walls. (b) Visualization of the preferential pathways through the geometry. The streamlines are colored according to the local flow velocities. (c) The spatial distribution of wall shear stress along the sinusoidal walls. Wall shear stresses remained mostly under $1 \mathrm{~Pa}$. 
Flow in r direction

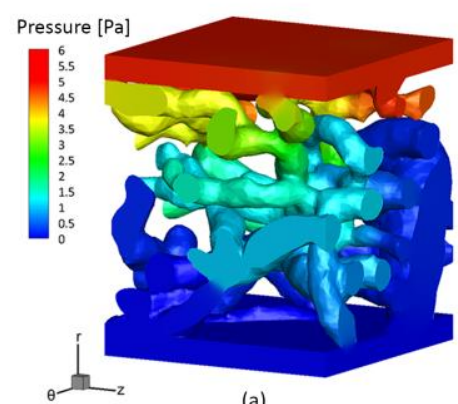

(a)
Flow in r direction

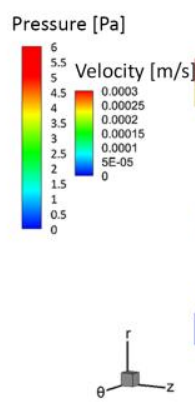

Flow in r direction

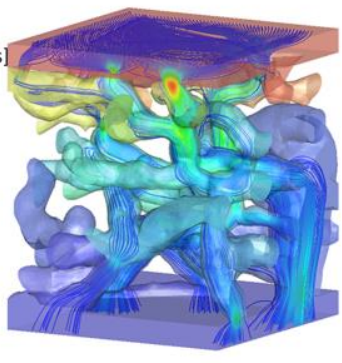

(b)
Flow in r direction

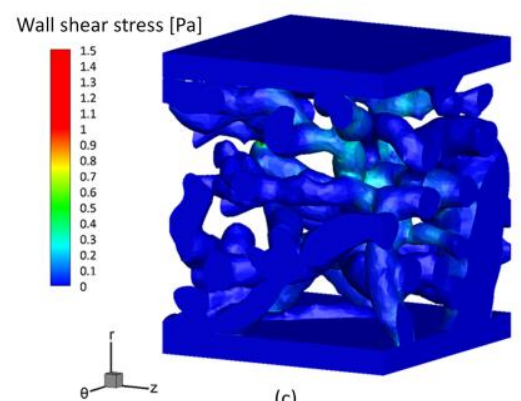

(c)

Figure 7. CFD models of cirrhotic sample 2 in the $r$ direction: (a) Static pressure distribution on the sinusoidal walls. (b) Visualization of the preferential pathways through the geometry. The streamlines are colored according to the local flow velocities. (c) The spatial distribution of wall shear stress along the sinusoidal walls. Wall shear stresses remained mostly under $1 \mathrm{~Pa}$.

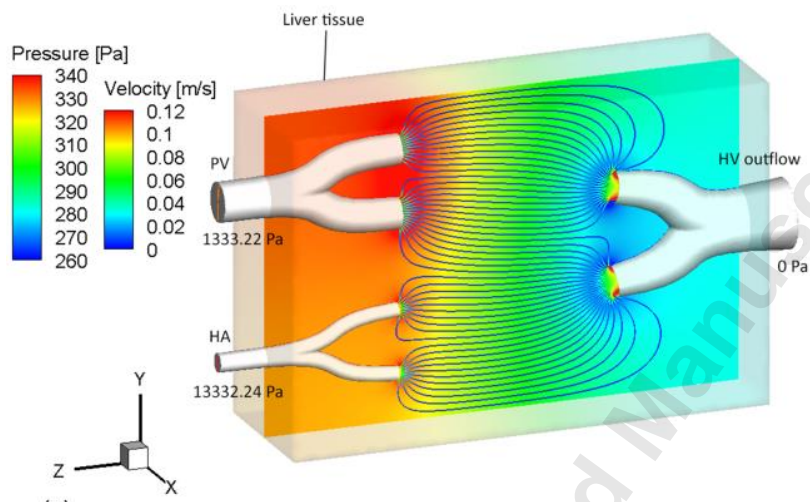

(a)

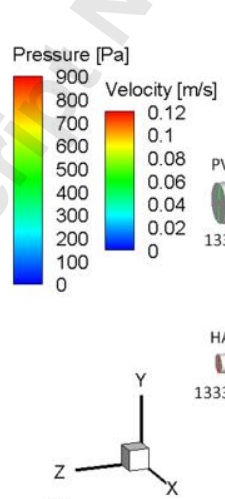

(b)

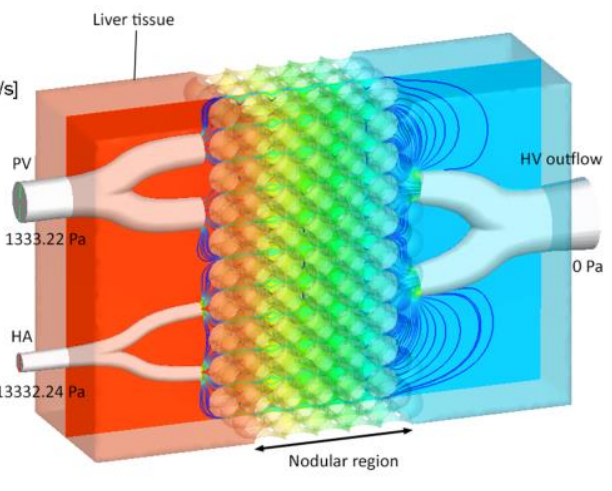

Figure 8. Pressure distribution and velocity streamlines of a section through (a) the sinusoidal region of the CFD model of a normal liver and $(\mathbf{b})$ the nodular region of the CFD model of a cirrhotic liver (simulation of severe cirrhosis with a nodular vol\% of $81.2 \%$ ). 

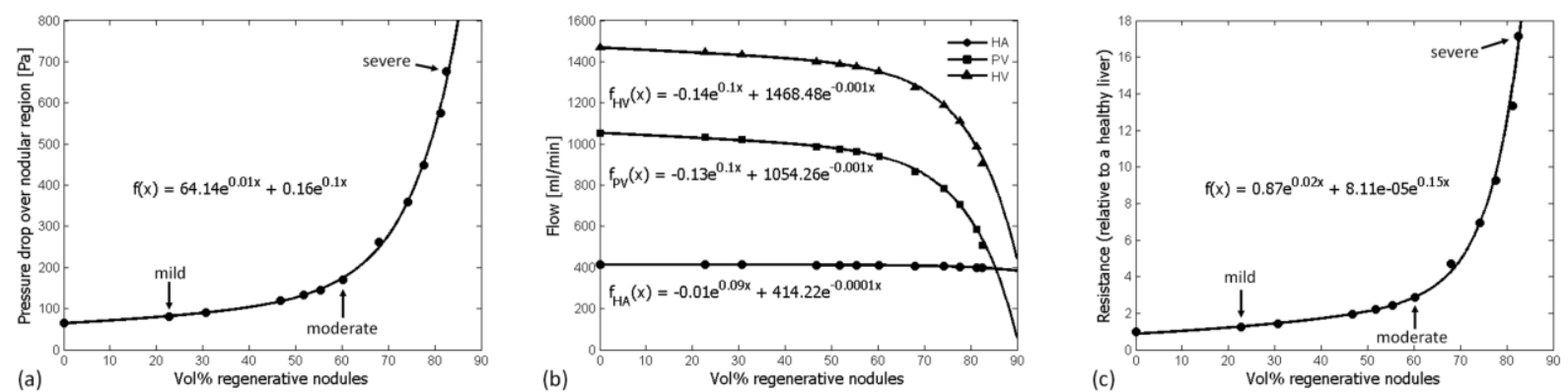

Figure 9. Results of the conceptual macrocirculation model. The pressure difference over the nodular region (a) increases and the flows through the vascular trees (b) decrease as a consequence of the regenerative nodules. Hence, the vascular resistance over the nodular region (c) increases due to regenerative nodules. 


\section{Acknowledgments}

This research was supported by the Agency for Innovation by Science and Technology in Flanders (IWT), Belgium. Diethard Monbaliu holds a chair of the Centrale Afdeling voor Fractionering (CAF), Vilvoorde, Belgium. Wim Laleman is a senior clinical investigator for the Fund for Scientific Research - Flanders. 


\section{Nomenclature}

$$
\begin{array}{ll}
\text { CFD } & =\text { computational fluid dynamics } \\
\mathrm{CT} & =\text { computed tomography } \\
\mathrm{HA} & =\text { hepatic artery } \\
\mathrm{HV} & =\text { hepatic vein } \\
\mathrm{IVR} & =\text { intrahepatic vascular resistance } \\
\mathrm{MRI} & =\text { magnetic resonance imaging } \\
\mathrm{NO} & =\text { nitric oxide } \\
\mathrm{PV} & =\text { portal vein } \\
V & =\text { velocity } \\
\text { WSS } & =\text { wall shear stress }
\end{array}
$$




\section{Table captions}

Table 1. The maximum and mean values of the velocity magnitude and wall shear stress for the smaller central cubes. 
A Multi-level Modeling Framework to Study Hepatic Perfusion Characteristics in case of Liver Cirrhosis

\section{Figure captions}

Figure 1. Cirrhotic liver (a) and the corresponding vascular corrosion cast (b). Smaller samples were dissected from the cast (white ellipse) to analyze the microcirculation.

Figure 2. Microscopic analysis of the cirrhotic angioarchitecture: scanning electron microscopic (SEM) image of enlarged, irregularly shaped intrahepatic vessels, most likely representing shunt vessels (a; dashed circle) causing blood flow to bypass hepatocytes, and an abnormal and bumpy blood vessel wall ( $b$; dashed circle). Microscopic images ( $c$; left and top right) and a SEM image (c; bottom right) show ellipsoidal holes which become visible after the maceration of the tissue in regenerative nodules, illustrating the compressed walls.

Figure 3. 3D reconstructions of dissected samples of the cirrhotic microvasculature based on micro-CT images: (a) sample 1 [resolution of $1.9 \mu \mathrm{m}$ ] containing seemingly unaffected sinusoids and (b) sample 2 [resolution of $1.7 \mu \mathrm{m}$ ] displaying abnormal shunt vessels (dashed circles).

Figure 4. Fluid domain in $r$-direction for sample 1 (a) and sample 2 (b). Inflow and outflow guidance boxes were added to facilitate solution convergence. The surface mesh density of both samples is displayed in the smaller frames. The red arrows indicate the flow direction (from top to bottom). The lateral boundaries were defined as symmetry planes.

Figure 5. Macrocirculation model of liver cirrhosis: (a) conceptual 3D model of the cirrhotic macrocirculation; $A_{1 / 2}$ and $I_{1 / 2}$ represent the branch's area and length for the first and second vessel generation, respectively. The indicated dimensions are shown in millimeter (mm). (b) Simplified electrical analog model of a healthy liver [28]. 
A Multi-level Modeling Framework to Study Hepatic Perfusion Characteristics in case of Liver Cirrhosis

Figure 6. CFD models of cirrhotic sample 1 in the $r$ direction: (a) Static pressure distribution on the sinusoidal walls. (b) Visualization of the preferential pathways through the geometry. The streamlines are colored according to the local flow velocities. (c) The spatial distribution of wall shear stress along the sinusoidal walls. Wall shear stresses remained mostly under $1 \mathrm{~Pa}$.

Figure 7. CFD models of cirrhotic sample 2 in the $r$ direction: (a) Static pressure distribution on the sinusoidal walls. (b) Visualization of the preferential pathways through the geometry. The streamlines are colored according to the local flow velocities. (c) The spatial distribution of wall shear stress along the sinusoidal walls. Wall shear stresses remained mostly under $1 \mathrm{~Pa}$.

Figure 8. Pressure distribution and velocity streamlines of a section through (a) the sinusoidal region of a normal liver and (b) the nodular region of a cirrhotic liver (simulation of severe cirrhosis with a nodular vol\% of $81.2 \%)$.

Figure 9. Results of the conceptual macrocirculation model. The pressure difference over the nodular region (a) increases and the flows through the vascular trees (b) decrease as a consequence of the regenerative nodules. Hence, the vascular resistance over the nodular region (c) increases due to regenerative nodules. 


\section{Supplemental material}

\section{Supplemental Table Captions}

Table S1. The resulting permeability coefficients $\left(k_{i j}\right)$ and 3D porosity $(\varepsilon)$ belonging to the subcubes of dissected sample 1 (seemingly unaffected sinusoids). The mean value, standard deviation, $p$ value (Shapiro-Wilk test) and median were also calculated for each permeability coefficient as well as the porosity.

Table S2. The permeability coefficients $\left(\mathrm{k}_{\mathrm{ij}}\right)$ and 3D porosity $(\varepsilon)$ belonging to the subsampled cubes of dissected sample 2 (abnormal vessels). The mean value, standard deviation, $\mathrm{p}$ value (Shapiro-Wilk test) and median were also calculated for each permeability coefficient as well as the porosity. (Subcube 9 (as defined in [9]) was omitted from the analysis, since there was no intersection between its outflow plane and the dissected sample, disabling calculating the pressure drop over the cube.) 
A Multi-level Modeling Framework to Study Hepatic Perfusion Characteristics in case of Liver Cirrhosis

\section{Supplemental Figure captions}

Figure S1. CFD models of cirrhotic sample 1: static pressure distribution on the sinusoidal walls.

Figure S2. Computational fluid dynamics models of cirrhotic sample 1: visualization of the preferential pathways through the geometry. The streamlines are colored according to the local flow velocities.

Figure S3. CFD models of cirrhotic sample 1: the spatial distribution of wall shear stress along the sinusoidal walls. Wall shear stresses remained mostly under $1 \mathrm{~Pa}$.

Figure S4. Hemodynamics of cirrhotic sample 2: static pressure distribution on the sinusoidal walls.

Figure S5. CFD models of cirrhotic sample 2: visualization of the preferential pathways through the geometry. The streamlines are colored according to the local flow velocities.

Figure S6. CFD models of cirrhotic sample 2: the spatial distribution of wall shear stress along the sinusoidal walls. Wall shear stresses remained mostly under $1 \mathrm{~Pa}$. 
A Nulti-level Modeling Framework to Study Hepatic Perfusion Characteristics in case of Liver Cirrhosis

\section{Supplemental Tables}

Table S1

\begin{tabular}{|c|c|c|c|c|c|c|c|c|c|c|}
\hline Cube & $k_{r r}\left[m^{2}\right]$ & $\mathrm{k}_{\theta \mathrm{r}}\left[\mathrm{m}^{2}\right]$ & $\mathrm{k}_{\mathrm{zr}}\left[\mathrm{m}^{2}\right]$ & $\mathrm{k}_{\mathrm{r} \theta}\left[\mathrm{m}^{2}\right]$ & $k_{\theta \theta}\left[m^{2}\right]$ & $\mathrm{k}_{\mathrm{z} \theta}\left[\mathrm{m}^{2}\right]$ & $\mathrm{K}_{\mathrm{rz}}\left[\mathrm{m}^{2}\right]$ & $\mathrm{k}_{\theta z}\left[\mathrm{~m}^{2}\right]$ & $\mathrm{k}_{\mathrm{zz}}\left[\mathrm{m}^{2}\right]$ & $\varepsilon$ \\
\hline 1 & $1.78 \mathrm{E}-13$ & 7.96E-14 & $-5.73 E-14$ & $1.92 \mathrm{E}-14$ & $5.24 \mathrm{E}-14$ & $-4.32 E-14$ & $-1.34 \mathrm{E}-14$ & $-9.42 E-14$ & 2.19E-13 & $1.65 \mathrm{E}-1$ \\
\hline 2 & $1.31 \mathrm{E}-13$ & $-5.16 \mathrm{E}-15$ & $2.45 \mathrm{E}-14$ & 5.34E-15 & $1.55 \mathrm{E}-13$ & $-2.95 E-14$ & $-1.03 E-14$ & $4.20 \mathrm{E}-16$ & $2.05 \mathrm{E}-14$ & $1.59 \mathrm{E}-1$ \\
\hline 3 & 8.51E-14 & $-3.33 \mathrm{E}-14$ & $2.18 \mathrm{E}-14$ & $-3.07 E-14$ & $6.94 \mathrm{E}-14$ & $-8.74 E-14$ & $9.63 \mathrm{E}-15$ & $-3.85 \mathrm{E}-14$ & 7.81E-14 & $2.04 \mathrm{E}-1$ \\
\hline 4 & $1.11 \mathrm{E}-13$ & $4.26 \mathrm{E}-14$ & $-5.40 \mathrm{E}-14$ & $2.40 \mathrm{E}-14$ & $5.90 \mathrm{E}-14$ & $-2.97 \mathrm{E}-14$ & $-1.79 E-15$ & $-3.33 \mathrm{E}-14$ & $2.76 \mathrm{E}-13$ & 1.12E-1 \\
\hline 5 & 8.84E-15 & $1.40 \mathrm{E}-15$ & $-6.93 E-15$ & $-3.73 E-14$ & $7.50 \mathrm{E}-14$ & $6.39 \mathrm{E}-15$ & $-4.16 \mathrm{E}-15$ & $-6.15 E-15$ & 1.35E-13 & $1.58 \mathrm{E}-1$ \\
\hline 6 & $8.55 \mathrm{E}-14$ & $1.58 \mathrm{E}-14$ & $5.55 \mathrm{E}-14$ & $-2.55 E-14$ & 8.26E-14 & $-3.40 \mathrm{E}-14$ & $6.16 \mathrm{E}-14$ & $-3.40 \mathrm{E}-14$ & $1.01 \mathrm{E}-14$ & $1.22 \mathrm{E}-1$ \\
\hline 7 & $9.73 \mathrm{E}-14$ & $8.22 \mathrm{E}-15$ & 3.69E-15 & $5.05 \mathrm{E}-15$ & $1.04 \mathrm{E}-13$ & $-2.29 E-14$ & $1.88 \mathrm{E}-14$ & $-2.59 \mathrm{E}-14$ & $1.18 \mathrm{E}-13$ & $1.24 \mathrm{E}-1$ \\
\hline 8 & $1.83 \mathrm{E}-14$ & $4.01 \mathrm{E}-14$ & $-1.41 \mathrm{E}-14$ & 3.09E-15 & 7.75E-14 & $-3.68 \mathrm{E}-14$ & 4.02E-14 & $-2.14 \mathrm{E}-14$ & $1.26 \mathrm{E}-13$ & 1.70E-1 \\
\hline 9 & 9.40E-15 & $-2.68 \mathrm{E}-15$ & 3.38E-15 & $-7.55 E-15$ & 5.67E-14 & $-2.64 E-14$ & 4.06E-14 & $-4.80 \mathrm{E}-14$ & $6.92 \mathrm{E}-14$ & $1.16 \mathrm{E}-1$ \\
\hline 10 & $1.28 \mathrm{E}-13$ & $-5.72 E-15$ & $-5.44 E-14$ & $-2.57 \mathrm{E}-14$ & $5.45 \mathrm{E}-14$ & $-2.80 \mathrm{E}-14$ & $-6.92 \mathrm{E}-15$ & $-5.37 E-14$ & $1.23 \mathrm{E}-13$ & $9.68 \mathrm{E}-2$ \\
\hline 11 & $6.87 \mathrm{E}-14$ & 3.37E-14 & $-2.12 \mathrm{E}-14$ & $6.45 \mathrm{E}-15$ & 4.84E-14 & $-3.68 \mathrm{E}-14$ & 5.53E-14 & $-6.76 \mathrm{E}-14$ & $1.95 \mathrm{E}-13$ & $1.50 \mathrm{E}-1$ \\
\hline 12 & 3.10E-14 & 7.31E-14 & $-8.42 \mathrm{E}-14$ & $3.13 \mathrm{E}-15$ & 4.53E-14 & $-2.10 \mathrm{E}-14$ & $3.71 \mathrm{E}-15$ & $-5.26 E-14$ & $1.53 \mathrm{E}-13$ & $1.31 \mathrm{E}-1$ \\
\hline 13 & $2.58 \mathrm{E}-13$ & $3.41 \mathrm{E}-14$ & $7.69 E-15$ & $-7.90 \mathrm{E}-15$ & 1.27E-13 & $-1.26 \mathrm{E}-13$ & $-4.40 \mathrm{E}-15$ & $-4.59 E-14$ & 1.67E-13 & $9.83 \mathrm{E}-2$ \\
\hline 14 & $1.12 \mathrm{E}-13$ & 1.16E-14 & $-2.05 E-14$ & $2.98 \mathrm{E}-14$ & $7.35 \mathrm{E}-14$ & $-4.63 E-14$ & $-1.79 \mathrm{E}-14$ & $-2.61 \mathrm{E}-14$ & $1.72 \mathrm{E}-13$ & $1.83 \mathrm{E}-1$ \\
\hline 15 & $1.04 \mathrm{E}-13$ & $5.84 \mathrm{E}-14$ & $1.05 \mathrm{E}-14$ & $-1.12 \mathrm{E}-15$ & $8.68 \mathrm{E}-14$ & $-3.96 E-14$ & $3.60 \mathrm{E}-14$ & $-1.19 \mathrm{E}-13$ & $2.34 \mathrm{E}-13$ & $1.53 \mathrm{E}-1$ \\
\hline Mean & $9.50 \mathrm{E}-14$ & $2.34 \mathrm{E}-14$ & $-1.24 \mathrm{E}-14$ & $-2.64 E-15$ & $7.78 \mathrm{E}-14$ & $-4.01 E-14$ & $1.38 \mathrm{E}-14$ & $-4.44 E-13$ & $1.58 \mathrm{E}-13$ & $1.43 \mathrm{E}-1$ \\
\hline Stdev & $6.66 \mathrm{E}-14$ & 3.18E-14 & 3.73E-14 & 2.00E-14 & 3.07E-14 & 3.06E-14 & 2.63E-14 & 3.12E-14 & 5.93E-14 & 3.15E-2 \\
\hline P-value & 2.11E-1 & 7.83E-1 & 7.81E-1 & 4.96E-1 & $2.88 \mathrm{E}-2$ & $2.68 \mathrm{E}-3$ & 7.76E-2 & 2.61E-1 & $9.25 \mathrm{E}-1$ & $7.24 \mathrm{E}-1$ \\
\hline Median & $9.73 \mathrm{E}-14$ & $1.58 \mathrm{E}-14$ & $-6.93 E-15$ & 3.09E-15 & 7.35E-14 & $-3.40 E-14$ & 3.71E-15 & $-3.85 E-14$ & $1.53 \mathrm{E}-13$ & 1.50E-1 \\
\hline
\end{tabular}

G. Peeters et al.

BIO-14-1475 
Table S2

\begin{tabular}{|c|c|c|c|c|c|c|c|c|c|c|}
\hline Cube & $k_{r r}\left[m^{2}\right]$ & $\mathrm{k}_{\theta \mathrm{r}}\left[\mathrm{m}^{2}\right]$ & $\mathrm{k}_{\mathrm{zr}}\left[\mathrm{m}^{2}\right]$ & $\mathrm{k}_{\mathrm{r} \theta}\left[\mathrm{m}^{2}\right]$ & $k_{\theta \theta}\left[m^{2}\right]$ & $\mathrm{k}_{\mathrm{z} \theta}\left[\mathrm{m}^{2}\right]$ & $\mathrm{K}_{\mathrm{rz}}\left[\mathrm{m}^{2}\right]$ & $\mathrm{k}_{\theta z}\left[\mathrm{~m}^{2}\right]$ & $\mathrm{k}_{\mathrm{zz}}\left[\mathrm{m}^{2}\right]$ & $\varepsilon$ \\
\hline 1 & $7.80 \mathrm{E}-13$ & $-2.40 \mathrm{E}-13$ & $-2.27 \mathrm{E}-13$ & 9.4 E-14 & $6.39 \mathrm{E}-13$ & $-2.79 E-13$ & $2.22 \mathrm{E}-13$ & $1.23 \mathrm{E}-13$ & $9.81 \mathrm{E}-13$ & $1.74 \mathrm{E}-1$ \\
\hline 2 & $1.64 \mathrm{E}-13$ & $-3.45 E-13$ & $2.79 \mathrm{E}-13$ & $-6.18 \mathrm{E}-15$ & $6.92 \mathrm{E}-14$ & $4.33 \mathrm{E}-14$ & $-7.12 \mathrm{E}-14$ & $8.84 \mathrm{E}-13$ & $1.78 \mathrm{E}-12$ & $3.74 \mathrm{E}-1$ \\
\hline 3 & $1.40 \mathrm{E}-12$ & $1.41 \mathrm{E}-12$ & $-6.44 \mathrm{E}-13$ & $5.59 \mathrm{E}-13$ & $9.88 \mathrm{E}-13$ & $-3.65 E-13$ & $-1.21 \mathrm{E}-13$ & $-1.84 \mathrm{E}-13$ & 5.97E-13 & $2.57 \mathrm{E}-1$ \\
\hline 4 & $1.68 \mathrm{E}-12$ & $-6.40 \mathrm{E}-13$ & $2.15 E-13$ & $3.23 E-13$ & $3.48 \mathrm{E}-13$ & $-5.22 \mathrm{E}-13$ & $-2.20 \mathrm{E}-14$ & $1.37 E-14$ & $8.25 \mathrm{E}-13$ & $2.84 \mathrm{E}-1$ \\
\hline 5 & $6.16 \mathrm{E}-13$ & $1.09 \mathrm{E}-13$ & $-9.02 E-14$ & $2.44 \mathrm{E}-13$ & $6.31 \mathrm{E}-13$ & $-2.16 \mathrm{E}-13$ & $3.91 \mathrm{E}-13$ & $-3.15 \mathrm{E}-14$ & $2.29 \mathrm{E}-13$ & $2.24 \mathrm{E}-1$ \\
\hline 6 & $1.47 \mathrm{E}-13$ & $6.53 \mathrm{E}-14$ & 3.07E-14 & $-3.33 \mathrm{E}-14$ & 2.97E-13 & $4.86 \mathrm{E}-14$ & $-1.78 \mathrm{E}-13$ & $1.63 \mathrm{E}-13$ & $3.47 \mathrm{E}-13$ & $1.11 \mathrm{E}-1$ \\
\hline 7 & $5.80 \mathrm{E}-14$ & $-4.78 \mathrm{E}-15$ & $-2.05 E-14$ & $1.06 \mathrm{E}-14$ & $2.72 \mathrm{E}-13$ & $5.75 \mathrm{E}-14$ & $-2.59 \mathrm{E}-13$ & $2.62 \mathrm{E}-14$ & $3.94 \mathrm{E}-13$ & $2.49 \mathrm{E}-1$ \\
\hline 8 & $5.44 \mathrm{E}-13$ & $4.67 \mathrm{E}-13$ & $7.72 \mathrm{E}-13$ & $-1.23 \mathrm{E}-13$ & $1.31 \mathrm{E}-12$ & $-4.15 E-13$ & $8.50 \mathrm{E}-13$ & $7.76 \mathrm{E}-13$ & $2.49 \mathrm{E}-12$ & $2.12 \mathrm{E}-1$ \\
\hline 10 & $2.02 \mathrm{E}-12$ & $9.02 \mathrm{E}-13$ & $-1.19 \mathrm{E}-12$ & $2.84 \mathrm{E}-13$ & $1.45 \mathrm{E}-12$ & $-9.14 \mathrm{E}-13$ & $3.76 \mathrm{E}-13$ & $-2.11 \mathrm{E}-13$ & $9.41 \mathrm{E}-13$ & $2.72 \mathrm{E}-1$ \\
\hline 11 & $1.27 \mathrm{E}-13$ & $-5.86 \mathrm{E}-14$ & $-1.22 \mathrm{E}-13$ & $1.84 \mathrm{E}-13$ & 7.67E-13 & $1.95 \mathrm{E}-14$ & $-2.07 \mathrm{E}-13$ & 3.37E-14 & $9.02 \mathrm{E}-13$ & $3.22 \mathrm{E}-1$ \\
\hline 12 & $8.65 E-13$ & $-2.38 \mathrm{E}-13$ & $-1.81 \mathrm{E}-13$ & $-2.06 \mathrm{E}-14$ & $4.68 \mathrm{E}-13$ & $-9.45 E-14$ & $3.05 E-13$ & $1.26 \mathrm{E}-13$ & $3.65 \mathrm{E}-13$ & $2.56 \mathrm{E}-1$ \\
\hline 13 & $4.35 \mathrm{E}-13$ & $-2.75 E-14$ & $-1.31 \mathrm{E}-13$ & $-3.28 \mathrm{E}-14$ & 4.57E-13 & 7.07E-14 & $-1.88 \mathrm{E}-13$ & $3.27 \mathrm{E}-13$ & 7.19E-13 & $1.38 \mathrm{E}-1$ \\
\hline 14 & $1.96 \mathrm{E}-13$ & $2.76 \mathrm{E}-14$ & $-9.21 \mathrm{E}-14$ & $6.91 \mathrm{E}-14$ & $3.87 \mathrm{E}-13$ & $-1.30 \mathrm{E}-13$ & $1.98 \mathrm{E}-13$ & $1.05 \mathrm{E}-13$ & $4.75 \mathrm{E}-13$ & $3.34 \mathrm{E}-2$ \\
\hline 15 & $5.28 \mathrm{E}-13$ & $2.30 \mathrm{E}-13$ & $1.08 \mathrm{E}-12$ & $2.21 \mathrm{E}-14$ & $1.11 \mathrm{E}-12$ & $-2.26 \mathrm{E}-13$ & $1.07 \mathrm{E}-13$ & $1.05 \mathrm{E}-12$ & $2.78 \mathrm{E}-12$ & $2.41 \mathrm{E}-1$ \\
\hline Mean & $6.83 \mathrm{E}-13$ & $1.18 \mathrm{E}-13$ & $-2.27 \mathrm{E}-14$ & $1.12 \mathrm{E}-13$ & $6.56 \mathrm{E}-13$ & $-2.09 E-13$ & $1.00 \mathrm{E}-13$ & $2.29 \mathrm{E}-13$ & $9.88 \mathrm{E}-13$ & $2.46 \mathrm{E}-1$ \\
\hline Stdev & $6.16 \mathrm{E}-13$ & $5.21 \mathrm{E}-13$ & $5.44 \mathrm{E}-13$ & $1.85 \mathrm{E}-13$ & $4.15 E-13$ & $2.80 \mathrm{E}-13$ & $3.12 \mathrm{E}-13$ & $3.93 E-13$ & 8.01E-13 & $7.28 \mathrm{E}-2$ \\
\hline P-value & $3.45 \mathrm{E}-2$ & $8.65 E-2$ & $2.55 \mathrm{E}-1$ & $1.06 \mathrm{E}-1$ & $3.41 \mathrm{E}-1$ & $5.50 \mathrm{E}-2$ & $1.43 \mathrm{E}-1$ & $1.37 \mathrm{E}-2$ & $5.23 \mathrm{E}-3$ & $9.58 \mathrm{E}-1$ \\
\hline Median & $5.36 \mathrm{E}-13$ & $1.14 \mathrm{E}-14$ & $-9.12 \mathrm{E}-14$ & $4.56 \mathrm{E}-14$ & $5.50 \mathrm{E}-13$ & $-1.73 E-13$ & $4.27 \mathrm{E}-14$ & $1.14 \mathrm{E}-13$ & $7.72 \mathrm{E}-13$ & $2.52 \mathrm{E}-1$ \\
\hline
\end{tabular}

G. Peeters et al.

BIO-14-1475 


\section{Supplemental Figures}
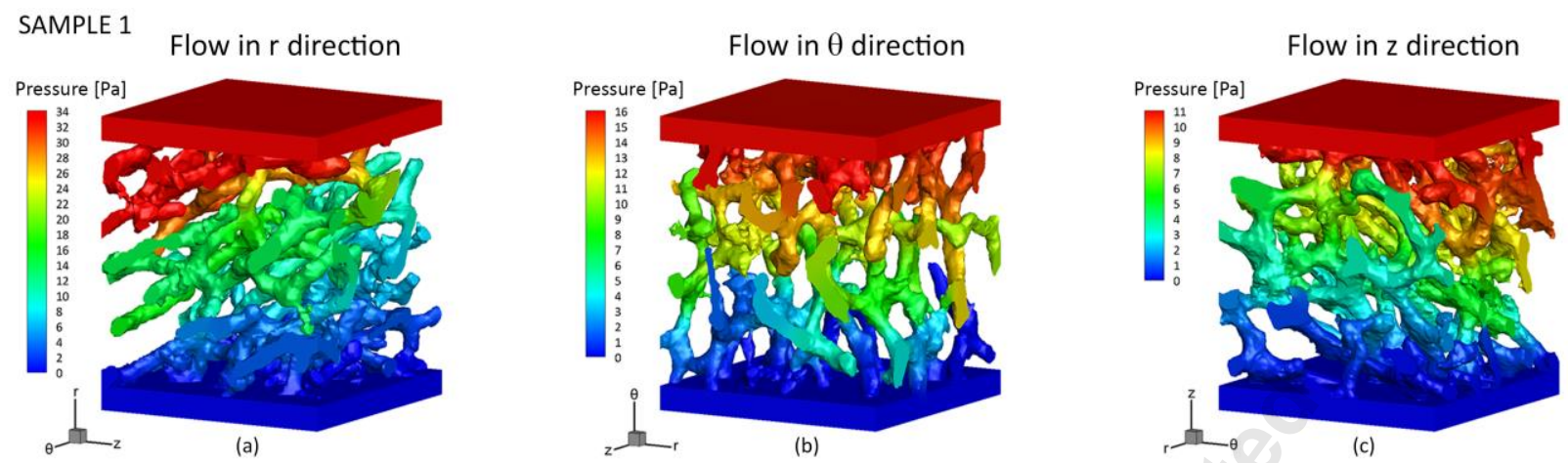

Figure S1. CFD models of cirrhotic sample 1: static pressure distribution on the sinusoidal walls.
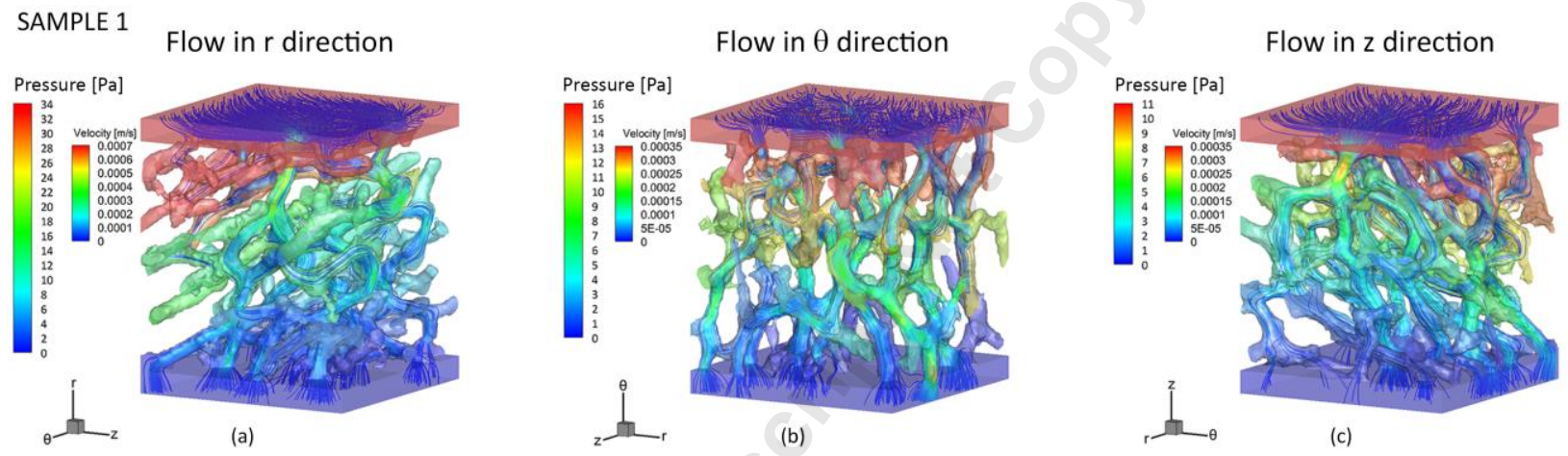

Figure S2. CFD models of cirrhotic sample 1: visualization of the preferential pathways through the geometry. The streamlines are colored according to the local flow velocities.
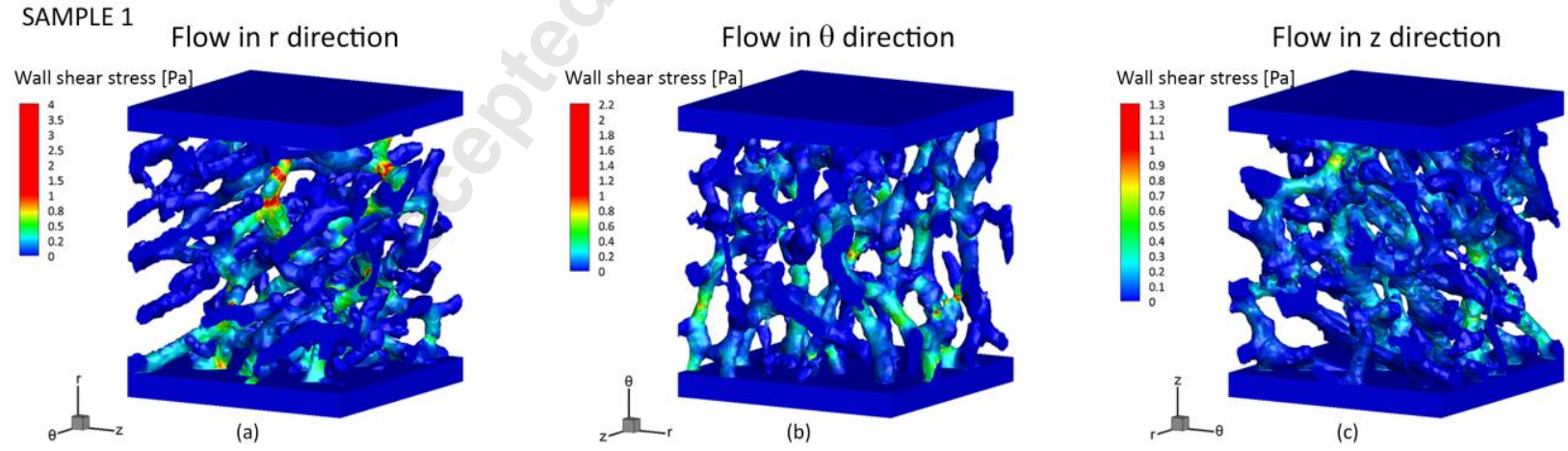

Figure S3. CFD models of cirrhotic sample 1: the spatial distribution of wall shear stress along the sinusoidal walls. Wall shear stresses remained mostly under $1 \mathrm{~Pa}$. 

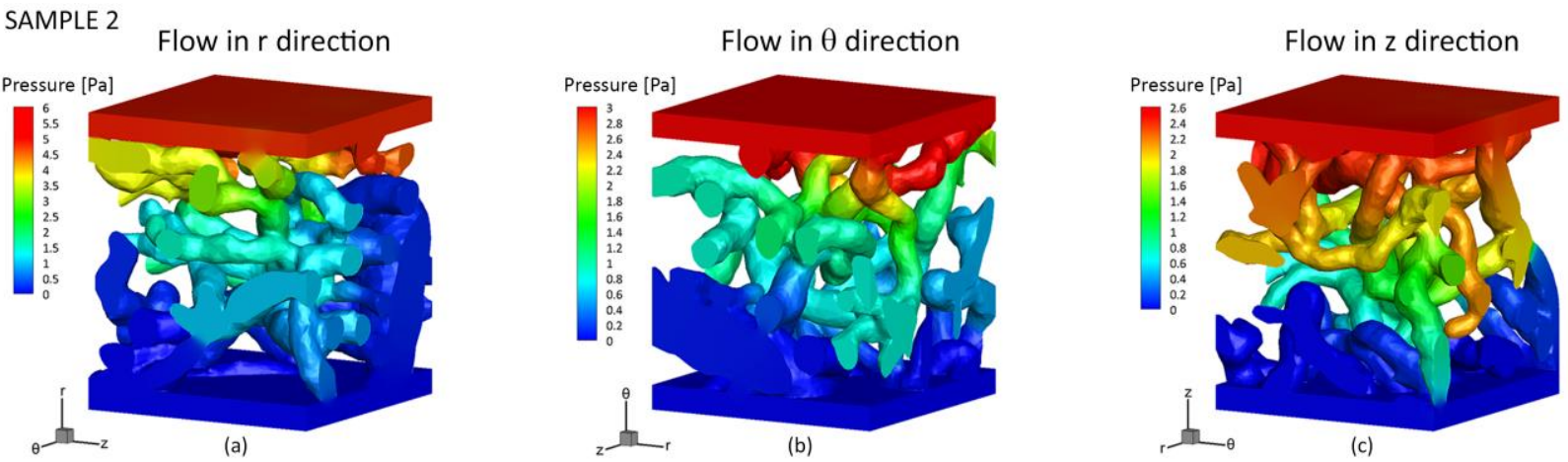

Figure S4. CFD models of cirrhotic sample 2: static pressure distribution on the sinusoidal walls.
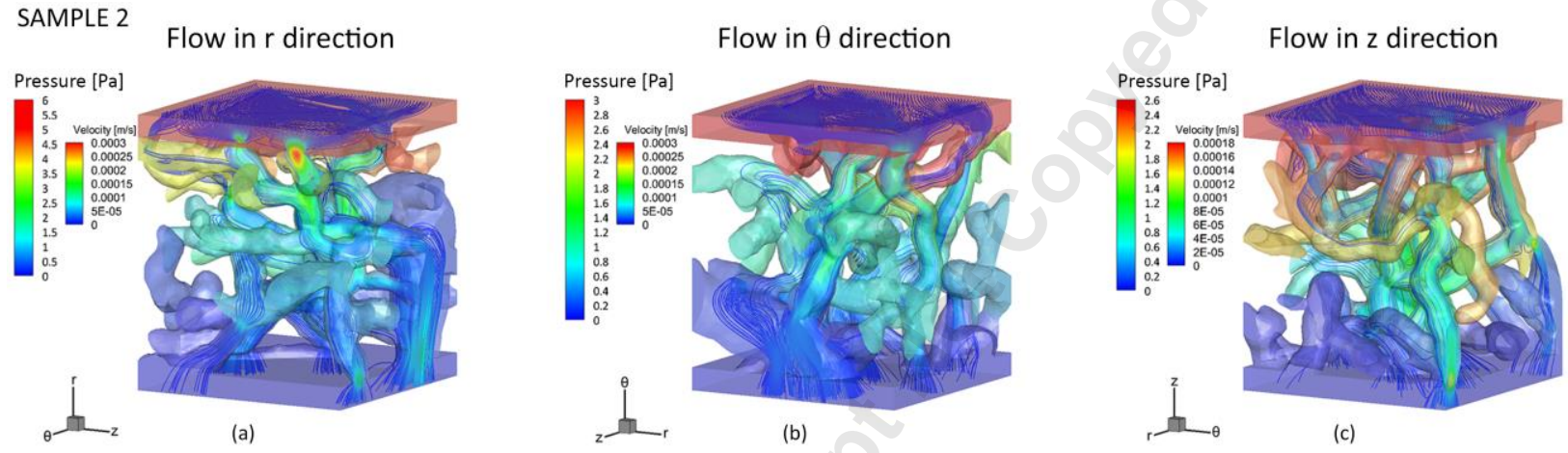

Figure S5. CFD models of cirrhotic sample 2: visualization of the preferential pathways through the geometry. The streamlines are colored according to the local flow velocities.
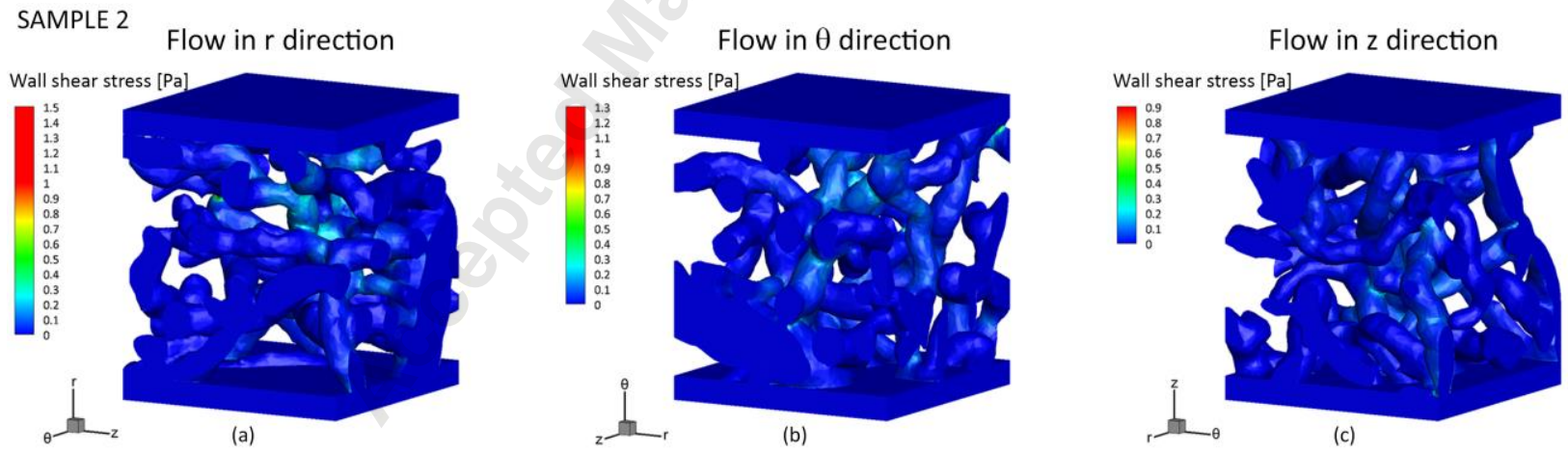

Figure S6. CFD models of cirrhotic sample 2: the spatial distribution of wall shear stress along the sinusoidal walls. Wall shear stresses remained mostly under $1 \mathrm{~Pa}$. 
A Multi-level Modeling Framework to Study Hepatic Perfusion Characteristics in case of Liver Cirrhosis

\section{References}

[1] Pinzani, M., Rosselli, M., and Zuckermann, M., 2011, "Liver cirrhosis," Best practice \& research. Clinical gastroenterology, 25(2), pp. 281-290.

[2] Thabut, D., and Shah, V., 2010, "Intrahepatic angiogenesis and sinusoidal remodeling in chronic liver disease: New targets for the treatment of portal hypertension?," Journal of hepatology, 53(5), pp. 976-980.

[3] Desmet, V. J., and Roskams, T., 2004, "Cirrhosis reversal: a duel between dogma and myth," Journal of hepatology, 40(5), pp. 860-867.

[4] Anthony, P. P., Ishak, K. G., Nayak, N. C., Poulsen, H. E., Scheuer, P. J., and Sobin, L. H., 1978, "The morphology of cirrhosis. Recommendations on definition, nomenclature, and classification by a working group sponsored by the World Health Organization," Journal of clinical pathology, 31(5), pp. 395-414.

[5] Minami, Y., and Kudo, M., 2012, "HCC Risk Factors," Biotargets of Cancer in Current Clinical Practice, p. 273.

[6] Ratib, S., West, J., Crooks, C. J., and Fleming, K. M., 2014, "Diagnosis of liver cirrhosis in England, a cohort study, 1998-2009: a comparison with cancer," The American journal of gastroenterology, 109(2), pp. 190-198.

[7] Tsochatzis, E. A., Bosch, J., and Burroughs, A. K., 2014, "Liver cirrhosis," Lancet, 383(9930), pp. 1749-1761.

[8] Pascher, A., Nebrig, M., and Neuhaus, P., 2013, "Irreversible liver failure: treatment by transplantation.," Deutsches Arzteblatt international, 110(10), pp. 167-173. 
A Multi-level Modeling Framework to Study Hepatic Perfusion Characteristics in case of Liver Cirrhosis

[9] Debbaut, C., Vierendeels, J., Casteleyn, C., Cornillie, P., Van Loo, D., Simoens, P., Van

Hoorebeke, L., Monbaliu, D., and Segers, P., 2012, "Perfusion characteristics of the human hepatic microcirculation based on three-dimensional reconstructions and computational fluid dynamic analysis," Journal of biomechanical engineering, 134(1), p. 011003.

[10] Marieb, E. N., and Hoehn, K., 2007, Human anatomy \& physiology, Pearson Education.

[11] Abdel-Misih, S. R., and Bloomston, M., 2010, "Liver anatomy," The Surgical clinics of North America, 90(4), pp. 643-653.

[12] Sherlock, S., and Dooley, J., 2008, Diseases of the liver and biliary system, John Wiley \& Sons.

[13] Lee, U. E., and Friedman, S. L., 2011, "Mechanisms of hepatic fibrogenesis," Best practice \& research. Clinical gastroenterology, 25(2), pp. 195-206.

[14] Huet, P. M., Goresky, C. A., Villeneuve, J. P., Marleau, D., and Lough, J. O., 1982,

"Assessment of liver microcirculation in human cirrhosis," The Journal of clinical investigation, 70(6), pp. 1234-1244.

[15] Villeneuve, J. P., Dagenais, M., Huet, P. M., Roy, A., Lapointe, R., and Marleau, D., 1996, "The hepatic microcirculation in the isolated perfused human liver," Hepatology, 23(1), pp. 2431.

[16] Vanheule, E., Geerts, A. M., Van Huysse, J., Schelfhout, D., Praet, M., Van Vlierberghe, H., De Vos, M., and Colle, I., 2008, "An intravital microscopic study of the hepatic microcirculation in cirrhotic mice models: relationship between fibrosis and angiogenesis," International journal of experimental pathology, 89(6), pp. 419-432. 
A Multi-level Modeling Framework to Study Hepatic Perfusion Characteristics in case of Liver Cirrhosis

[17] Varin, F., and Huet, P. M., 1985, "Hepatic microcirculation in the perfused cirrhotic rat liver," The Journal of clinical investigation, 76(5), pp. 1904-1912.

[18] Annet, L., Materne, R., Danse, E., Jamart, J., Horsmans, Y., and Van Beers, B. E., 2003, "Hepatic flow parameters measured with MR imaging and Doppler US: correlations with degree of cirrhosis and portal hypertension," Radiology, 229(2), pp. 409-414.

[19] Fischer, M. A., Donati, O. F., Reiner, C. S., Hunziker, R., Nanz, D., and Boss, A., 2012, "Feasibility of semiquantitative liver perfusion assessment by ferucarbotran bolus injection in double-contrast hepatic MRI," Journal of magnetic resonance imaging : JMRI, 36(1), pp. 168-176. [20] Ma, G., Bai, R., Jiang, H., Hao, X., Ling, Z., and Li, K., 2013, "Assessment of hemodynamics in a rat model of liver cirrhosis with precancerous lesions using multislice spiral CT perfusion imaging," BioMed research international, 2013, p. 813174.

[21] Chen, M. L., Zeng, Q. Y., Huo, J. W., Yin, X. M., Li, B. P., and Liu, J. X., 2009, "Assessment of the hepatic microvascular changes in liver cirrhosis by perfusion computed tomography," World journal of gastroenterology : WJG, 15(28), pp. 3532-3537.

[22] Ying, M., Leung, G., Lau, T. Y., Tipoe, G. L., Lee, E. S., Yuen, Q. W., Huang, Y. P., and Zheng, Y. P., 2012, "Evaluation of liver fibrosis by investigation of hepatic parenchymal perfusion using contrast-enhanced ultrasound: an animal study," Journal of clinical ultrasound : JCU, 40(8), pp. 462-470.

[23] Ridolfi, F., Abbattista, T., Busilacchi, P., and Brunelli, E., 2012, "Contrast-enhanced ultrasound evaluation of hepatic microvascular changes in liver diseases," World journal of gastroenterology : WJG, 18(37), pp. 5225-5230. 
A Multi-level Modeling Framework to Study Hepatic Perfusion Characteristics in case of Liver Cirrhosis

[24] Ho, C. M., Lin, R. K., Tsai, S. F., Hu, R. H., Liang, P. C., Sheu, T. W., and Lee, P. H., 2010, "Simulation of portal hemodynamic changes in a donor after right hepatectomy," Journal of biomechanical engineering, 132(4), p. 041002.

[25] Ho, C. M., Tsai, S. F., Lin, R. K., Liang, P. C., Sheu, T. W., Hu, R. H., and Lee, P. H., 2007, "Computer simulation of hemodynamic changes after right lobectomy in a liver with intrahepatic portal vein aneurysm," Journal of the Formosan Medical Association = Taiwan yi zhi, 106(8), pp. 617-623.

[26] Ho, H., Sorrell, K., Bartlett, A., and Hunter, P., 2012, "Blood flow simulation for the liver after a virtual right lobe hepatectomy," Medical image computing and computer-assisted intervention : MICCAI ... International Conference on Medical Image Computing and ComputerAssisted Intervention, 15(Pt 3), pp. 525-532.

[27] Kennedy, A. S., Kleinstreuer, C., Basciano, C. A., and Dezarn, W. A., 2010, "Computer modeling of yttrium-90-microsphere transport in the hepatic arterial tree to improve clinical outcomes," International journal of radiation oncology, biology, physics, 76(2), pp. 631-637. [28] Debbaut, C., Monbaliu, D., Casteleyn, C., Cornillie, P., Van Loo, D., Masschaele, B., Pirenne, J., Simoens, P., Van Hoorebeke, L., and Segers, P., 2011, "From vascular corrosion cast to electrical analog model for the study of human liver hemodynamics and perfusion," IEEE transactions on bio-medical engineering, 58(1), pp. 25-35.

[29] Ho, H., Sorrell, K., Bartlett, A., and Hunter, P., 2013, "Modeling the hepatic arterial buffer response in the liver," Medical engineering \& physics, 35(8), pp. 1053-1058.

[30] Debbaut, C., De Wilde, D., Casteleyn, C., Cornillie, P., Van Loo, D., Van Hoorebeke, L., Monbaliu, D., Fan, Y. D., and Segers, P., 2012, "Modeling the impact of partial hepatectomy on 
A Multi-level Modeling Framework to Study Hepatic Perfusion Characteristics in case of Liver Cirrhosis

the hepatic hemodynamics using a rat model," IEEE transactions on bio-medical engineering, 59(12), pp. 3293-3303.

[31] Bonfiglio, A., Leungchavaphongse, K., Repetto, R., and Siggers, J. H., 2010, "Mathematical modeling of the circulation in the liver lobule," Journal of biomechanical engineering, 132(11), p. 111011.

[32] Siggers, J. H., Leungchavaphongse, K., Ho, C. H., and Repetto, R., 2013, "Mathematical model of blood and interstitial flow and lymph production in the liver," Biomechanics and modeling in mechanobiology.

[33] Ricken, T., Dahmen, U., and Dirsch, O., 2010, "A biphasic model for sinusoidal liver perfusion remodeling after outflow obstruction," Biomechanics and modeling in mechanobiology, 9(4), pp. 435-450.

[34] Rani, H. P., Sheu, T. W., Chang, T. M., and Liang, P. C., 2006, "Numerical investigation of non-Newtonian microcirculatory blood flow in hepatic lobule," Journal of biomechanics, 39(3), pp. 551-563.

[35] Van Steenkiste, C., Trachet, B., Casteleyn, C., van Loo, D., Van Hoorebeke, L., Segers, P., Geerts, A., Van Vlierberghe, H., and Colle, I., 2010, "Vascular corrosion casting: analyzing wall shear stress in the portal vein and vascular abnormalities in portal hypertensive and cirrhotic rodents," Laboratory investigation; a journal of technical methods and pathology, 90(11), pp. 1558-1572.

[36] Debbaut, C., Vierendeels, J., Siggers, J. H., Repetto, R., Monbaliu, D., and Segers, P., 2012, "A 3D porous media liver lobule model: the importance of vascular septa and anisotropic 
A Multi-level Modeling Framework to Study Hepatic Perfusion Characteristics in case of Liver Cirrhosis

permeability for homogeneous perfusion," Computer methods in biomechanics and biomedical engineering.

[37] Masschaele, B., Cnudde, V., Dierick, M., Jacobs, P., Van Hoorebeke, L., and Vlassenbroeck, J., 2007, "UGCT: New X-ray radiography and tomography facility," Nuclear Instruments and Methods in Physics Research Section A: Accelerators, Spectrometers, Detectors and Associated Equipment, 580(1), pp. 266-269.

[38] Debbaut, C., Segers, P., Cornillie, P., Casteleyn, C., Dierick, M., Laleman, W., and Monbaliu, D., 2014, "Analyzing the human liver vascular architecture by combining vascular corrosion casting and micro-CT scanning: a feasibility study," Journal of anatomy. [39] van der Plaats, A., t Hart, N. A., Verkerke, G. J., Leuvenink, H. G., Verdonck, P., Ploeg, R. J., and Rakhorst, G., 2004, "Numerical simulation of the hepatic circulation," The International journal of artificial organs, 27(3), pp. 222-230.

[40] Debbaut, C., Monbaliu, D., and Segers, P., 2013, "Hydraulic input impedances as a tool to capture liver graft perfusion properties," 12th Belgian National Day on Biomedical EngineeringBrussels.

[41] Goldsmith, H. L., Cokelet, G. R., and Gaehtgens, P., 1989, "Robin Fahraeus: evolution of his concepts in cardiovascular physiology," The American journal of physiology, 257(3 Pt 2), pp. H1005-1015.

[42] Debbaut, C., 2013, "Multi-level modelling of hepatic perfusion in support of liver transplantation strategies," Ghent University. 
Copyright (c) 20 A Multi-level Modeling Framework to Study Hepatic Perfusion Characteristics in case of Liver Cirrhosis

[43] Laleman, W., Vander Elst, I., Zeegers, M., Servaes, R., Libbrecht, L., Roskams, T., Fevery, J., and Nevens, F., 2006, "A stable model of cirrhotic portal hypertension in the rat: thioacetamide revisited," European journal of clinical investigation, 36(4), pp. 242-249. 